\title{
A Framework for Utilizing Fire Property Tests
}

\author{
Thomas G. Cleary \\ James G. Quintlere \\ U.8. DEPARTMENT OF COMMERCE \\ Nationd Institute of standards \\ and Technoloety \\ Building and Fire Research Laboratory \\ Caitherabure, MD 20899
}





\section{A Framework for Utilizing Fire Property Tests}

Thomas G. Cleary James G. Quintiere

US. DEPARTMENT OF COMMERCE Mational Instltute of standards and Technolory Building and Fire Research Laboratory Gaithersbure, MD 20899

Augrust 1991

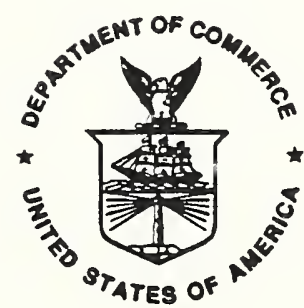

U.S. DEPARTMENT OF COMMERCE Robert A Mosbacher, Secretery MANONA INSTIUU: OF STAMDARD: NND TECHNOLOCY

sohn $W_{0}$ Lyon: Directos 


\section{Page}

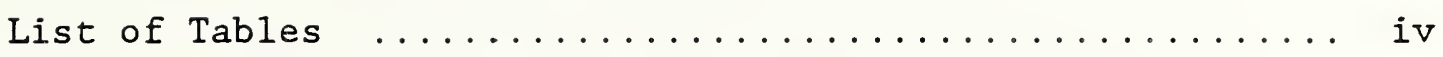

List of Figures $\ldots \ldots \ldots \ldots \ldots \ldots \ldots \ldots \ldots \ldots \ldots \ldots \ldots$

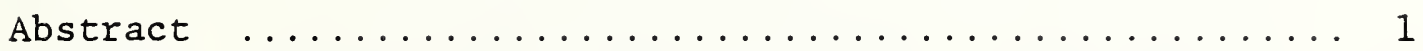

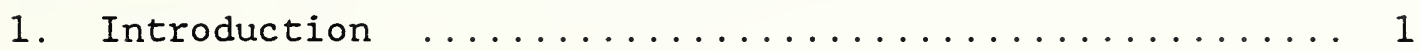

2. Theoretical Development $\ldots \ldots \ldots \ldots \ldots \ldots \ldots \ldots \ldots$

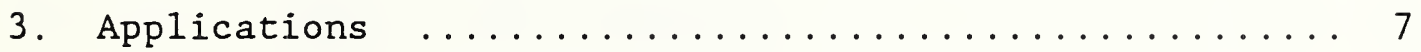

3.1 Ful1 Scale Room - Corner Tests .......... 7

3.2 PMMA Room Wall Test ................ 8

3.3 Textile Wall Covering Room Tests .......... 9

4. Concluding Remarks .................... 10

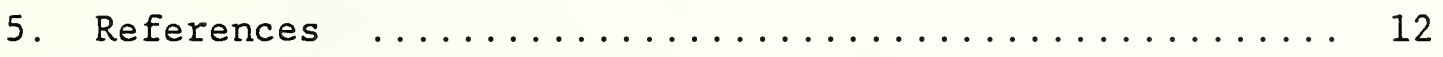

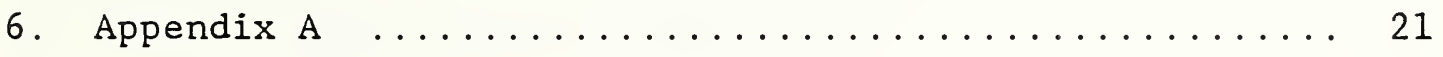

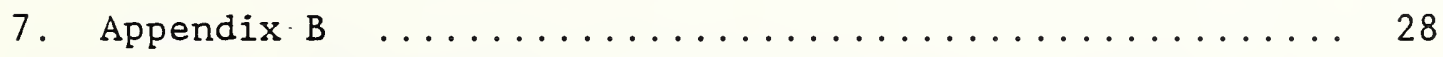




\section{LIST OF TABLES}

Table 1. Fire Properties of Swedish Fire Test Materials

Table 2. Time to Achieve a $1 \mathrm{MW}$ Fire in the Swedish Fire Tests

Table 3. Textile Wall Coverings Room Fire Tests 


\section{LIST OF FIGURES}

Figure 1. Energy Release Property Data

Figure 2. Model Floor, Wall, and Ceiling Configurations

Figure 3. Energy Release Predictions for the Boràs Data

Figure 4. Growth of the Pyrolysis Area on a PMMA Wall

Figure A-1. Rate of Heat Release vs. Time for a Particle Board Lined Room

Figure A-2. Rate of Heat Release vs. Time for a Insulating Fiberboard Lined Room

Figure A-3. Rate of Heat Release vs. Time for a Medium Density Fiberboard Lined Room

Figure A-4. Rate of Heat Release vs. Time for a Wood Paneling Lined Room

Figure A-5. Rate of Heat Release vs. Time for a Melamine Faced Particle Board Lined Room

Figure A-6. Rate of Heat Release vs. Time for a. Paper Faced Gypsum Board Lined Room.

Figure A-7. Rate of Heat Release Vs. Time for a PVC Faced Gypsum Board Lined Room

Figure A-8. Rate of Heat Release vs. Time for a Textile Covering Mounted on Gypsum Board Lined Room

Figure A-9. Rate of Heat Release vs. Time for a Textile Covering Mounted on Mineral Wool Lined Room

Figure A-10. Rate of Heat Release vs. Time for a Paper Covered Particle Board Lined Room

Figure A-11. Rate of Heat Release vs. Time for a Rigid Polyurethane Foam Lined Room.

Figure A-12. Rate of Heat Release vs. Time for an Expanded Polystyrene Lined Room

Figure B-1. Time to Reach Ignition Temperature for PMMA Wall 



\title{
A Framework for Utilizing Fire Property Tests
}

\author{
Thomas G. Cleary \\ Building and Fire Research Laboratory \\ National Institute of Standards and Technology \\ Gaithersburg, MD 20899 \\ and \\ James G. Quintiere \\ Department of Fire Protection Engineering \\ University of Maryland \\ College Park, MD 20742
}

\begin{abstract}
A complete approximate set of equations is developed to describe fire spread over a surface and its resultant energy release. Wall, floor, and ceiling orientations are considered. The needed model data are couched in terms of available test method results, e.g., Cone Calorimeter and LIFT apparatuses. Several applications are presented to show how energy release rates can be predicted and how well they represent real data from full-scale and model room lining experiments.
\end{abstract}

Key Words: Heat release, flammability tests, fire prediction, linings, room fires.

\section{INTRODUCTION}

Traditionally, fire test methods have been used to provide relative rankings of material and product performance from which officials have defined safety requirements. This process has been empirical relying on judgement and fire experience. Although, one would expect fire safety to be consistent, each regulatory agency or government has laid out its own tests and procedures creating an array of different results. Test methods stand more on their longevity, than on their scientific merits. This is an unsound technical situation which can compromise safety. The solution to this state of affairs is, however, not readily accessible since a technical consensus has not yet been developed from the science of fire. Hence, a complete scientific alternative is not yet possible, but a framework for an alternative can be developed in terms of available scientific information and methods. We will present such a framework and demonstrate its utility and level of accuracy. 
Theories of flame spread and new widely used test apparatuses capable of providing engineering fire property data make it feasible to construct a framework for fire hazard assessment. The test apparatuses include the Cone Calorimeter [1], and the Lateral Ignition and Flame Spread Test (LIFT) [2], both of which have been recently established as ASTM standard methods and are being considered in ISO. We shall not review the details of these apparatuses here, it only suffices that they can produce the needed data in the analysis to follow. That analysis will be confined to fire growth on flat materials in applications of floors, walls and ceilings. We shall formulate a model to compute the "output" of the fire growth as a function of time in terms of the material orientation and properties. The "output" can be defined as appropriate for the hazard. In the exercises to follow we shall address the output as energy release rate representative of the hazard of rapid fire growth or perhaps flashover.

The model to be presented, we emphasize, represents only a framework for a more complete and precise solution to the appropriate characterization of materials through fire test methods. But once formulated, we tested the model against various data sets for full scale behavior of fire growth on lining materials in rooms. Our results and our model should serve as support for other analyses which have used similar property data to predict the flashover times for some of these experiments [3-5]. However, we believe that our model is less empirical and more physically complete than these previous analyses [3-5], and the accuracy of the end results is comparable. Indeed, it suggests that we all have selected the key properties in our analyses which illustrates the value of the new fire property tests in supplying useful and versatile engineering data. Hence, future models should be able to build improvement on this base. Finally, our model will be capable of coping with changing environmental conditions, but we shall not implement this in any dynamic sense by coupling its fire growth to the changing conditions of a room involved in fire. However, we will examine some effects of pre-heating during flame spread that could come as a result of thermal feedback due to a confined fire.

\section{THEORETICAL DEVELOPMENT}

Initially the purpose of the analysis to follow was to illustrate how fire property test data could be used in modeling to yield meaningful quantitative results for assessing fire safety. As will be seen, the use of the analysis is capable of producing very accurate results. This probably resulted from our approach of keeping the model simple but complete. We have included the essential elements of fire growth; namely, ignition, energy release rate, burning time, and all relevant modes of flame spread for the surface orientation considered. Also, we have included effects of the ignition fire source, and have considered parametrically, the effects of thermal feedback. Detailed transient characteristics and room smoke layering have been ignored, but these effects could easily be included in a more refined analysis and their contributions assessed. However, it can be argued that their impact is likely to be secondary, but ultimately needs to be examined. 
Fire Properties:

The term "fire properties" has been used, but we need to define it in context. Generally, engineering property data constitute physical and chemical parameters, usually arising from thermodynamic principles or rate process models. Although we could couch our analysis in terms of such true properties, we choose to use more directly measurable quantities since fire modeling is not yet complete enough to deal with complex materials. Hence, our "fire properties" will not necessarily be valid engineering properties and will depend on environmental conditions. We will identify these "fire properties" as we develop our theory. As an introduction, we list them now:

1. $\bar{Q} "$, average peak heat release rate per unit area

This value is derived from a device like the Cone Calorimeter [1] for which the transient data have been averaged, and evaluated at a specified irradiance level. It is illustrated in Figure 1 in which the area under the actual curve is approximately equal to the area under the rectangle. We have not used a standardized prescription for determining the average energy release rate and burn time. This was done in a consistent manner by approximating the significant burning region of the curve by a square wave. We selected an average maximum for $\dot{Q} "$ and then estimated $t_{b}$ to maintain the total energy.

2. $t_{b}$, burn time

This value is the width of the approximating rectangle in Figure 1 . This also corresponds to a given heat flux, and is derivable from the Cone Calorimeter.

3. $t_{i g}$, ignition time

This value is the time for piloted ignition at a given heat flux, specifically radiative. The heat flux level should be selected to correspond to the flame heat flux level appropriate to wind-aided flame spread. This will be defined more specifically later. This "property" can be derived from a number of ignition apparatuses without any loss in uniqueness since it should not be very dependent on the apparatus (e.g., Cone Calorimeter [1], [2]) provided the radiant emission spectrum of the apparatus is similar.

4. $\Phi$, flame heating parameter in opposed flow spread

This "property" is directly derivable from the LIFT [2,6] standard procedure. It represents the flame heat transfer and opposed flow velocity effects. In the IIFT mode, the flow velocity corresponds to a natural convection condition, and experience suggests that the $\Phi$ is not strongly sensitive to surface orientation.

\section{5. $T_{s, m i n}$, minimum temperature for flame spread}

In opposed flow flame spread it is found that, in general, materials require a minimum heating level to achieve a surface temperature required for spread. Below this temperature spread is not possible. Above this temperature and up to the ignition temperature $\left(T_{i g}\right)$ of the material is the domain of surface 
temperatures where surface flame spread theory applies. For external heating conditions that lead to the attainment of the ignition temperature, a gasphase flammable mixture can result with flame propagation still possible as is a "gas-phase" phenomenon in contrast to surface spread that we are considering here. Although this property, $T_{s, m i n}$, can be derived from the LIFT for opposed flow spread, it is also required but not available for, wind-aided or upward flame spread. For example, it appears that a pre-heated surface temperature in excess of $80^{\circ} \mathrm{C}$ is necessary to cause sustained upward flame spread on wood particle board [7].

Equations:

In developing the governing equations we shall consider all materials to be thermally thick, i.e. no effect of thickness, and laminated materials and substrates are treated as homogeneous, reflective of their bulk properties. The same corresponding equations will apply, without distinction, to horizontal (floor), lateral and downward wall spread as opposed flow spread; and to upward wall and ceiling spread as wind-aided spread. One might argue with this lack of distinction but the opposed flow case for these different orientations has some support [8] whereas the extension of the upward spread theory to the ceiling is only a convenience for now which needs further study. For all orientations, as illustrated in Figure 2, symmetry is invoked, and the wind-aided coordinate is designated by $y$ and the opposed flow coordinate by $x$. Spread on the floor (Fig. 2a), and ceiling (Fig. 2b) is radially symmetric, and on the wall (Fig. 2c) is approximated as a region developed from two linear ( $x$ and $y$ ) spreads away from an initially ignited rectilinear zone of area $2 \mathrm{x}_{\mathrm{o}} \mathrm{y}_{0}$. The region between the extended pyrolysis wall fronts $\left(\mathrm{x}_{\mathrm{p}}, \mathrm{y}_{\mathrm{p}}\right)$, and the burn-out fronts $\left(\mathrm{x}_{\mathrm{b}}, \mathrm{y}_{\mathrm{b}}\right)$ is formed by straight line approximations as illustrated in Figure $2 c$.

The objective of our analysis is to compute the energy release rate, $\dot{Q}(t)$, as a function of time for the orientation shown in Figure 2 or their combination. For energy release we write the following approximation based on Figure 1.

$$
\dot{Q}(t)=\iint \dot{Q} " d x d y=\dot{Q}^{\prime \prime} A_{p}
$$

where $A_{p}$ is the pyrolysis or volatilizing area.

For the floor or ceiling cases it can easily be shown that

$$
A_{p}=\pi\left(x_{p}^{2}-x_{b}^{2}\right) \text { or } \pi\left(y_{p}^{2}-y_{b}^{2}\right)
$$

For the wall case,

or

$$
\begin{array}{llrl}
A_{p}=2\left[y_{p} x_{0}+\left(x_{p}-x_{0}\right) y_{0}+1 / 2\left(y_{p}-y_{o}\right)\left(x_{p}-x_{0}\right)\right] & \text { for } t \leq t_{b} \\
A_{p}=2\left[y_{p} x_{0}+x_{p} y_{0}+1 / 2\left(y_{p}-y_{0}\right)\left(x_{p}-x_{0}\right)\right] & & \text { for } t>t_{b} \\
& -2\left[y_{b} x_{0}+x_{b} y_{0}+1 / 2\left(y_{b}-y_{0}\right)\left(x_{b}-x_{0}\right)\right] & &
\end{array}
$$

In order to formulate the rest of the analysis we write out and solve the equations for the pyrolysis and burnout fronts. 
Wind-aided Solution:

The upward or wind-aided solution is developed [9] from the equation

$$
\frac{d y_{p}}{d t}=\frac{y_{f}-y_{p}}{t_{i g}}
$$

where $y_{f}$ is the position of the flame tip with $y_{f}-y_{p}$ defining the forward heat transfer region of the flame identified with heat flux, $\dot{q}_{f}^{\prime \prime}$. Equation (4) is a quasi-steady model which uses the steady-state flame spread result successively over time and the forward heat transfer region changes. Mathematically, this solution is continuous. This flame heat flux will be taken as $30 \mathrm{~kW} / \mathrm{m}^{2}$ in our analysis for all materials.

The ignition time is given as

$$
t_{i g}=\frac{\pi k \rho c\left(T_{i g}-T_{s}\right)^{2}}{4\left(q_{f}^{\prime \prime}\right)^{2}}
$$

where $T_{i g}$ is the ignition temperature, $k \rho c$ is the thermal inertia, and $T_{s}$ is the surface temperature of the region $y \geq y_{f}$. As can be seen, the "property" $t_{i g}$ can be related to more valid engineering materials properties ( $k \rho c$ and $\mathrm{T}_{\mathrm{ig}}$ ) and other factors.

Finally, the flame length can be estimated by a linear approximation to wall fire data [9] as

$$
\mathrm{y}_{f}-\mathrm{y}_{\mathrm{b}}=\mathrm{k}_{\mathrm{f}}\left[\dot{\mathrm{Q}}_{\mathrm{o}}^{\prime}+\overline{\mathrm{Q}}^{\prime \prime}\left(\mathrm{y}_{\mathrm{p}}-\mathrm{y}_{\mathrm{b}}\right)\right]
$$

where $y_{b}$ is taken as identically zero for $t \leq t_{b}$, and $\dot{Q}_{0}^{\prime}$ is the energy release rate per unit width of the ignitor flame needed to start the process. This ignitor flame is assumed to provide a uniform heat flux $\dot{q}_{f}^{\prime \prime}=30 \mathrm{~kW} / \mathrm{m}^{2}$ over the region $\left(x_{0}, y_{0}\right)$ which is taken to ignite at $t=t_{i g}$ in Eq. (5), or corresponding to $t_{i g}$ in Figure 1 . The value for $k_{f}$ is approximately $0.01 \mathrm{~m}^{2} / \mathrm{kW}$. In Equation (6), the term $\dot{Q}_{0}^{\prime}$ is set to zero after $t=t_{b}$. This is done after $t=$ $t_{b}$ since the initial region as determined by the flame extent due to $\dot{Q}_{0}^{\prime}$ is no longer burning, and subsequently the ignitor flame would become discontinuous from the material flame ahead of this region. This ignitor energy is consistently included in the overall heat release.

The burnout front can be approximated as

$$
\frac{d y_{b}}{d t}=\frac{y_{p}-y_{b}}{t_{b}} \quad \text { for } t>t_{b}
$$

The initial conditions are given as:

and

$$
\begin{aligned}
& t=0, y_{p}=y_{0} \\
& t=t_{b}, y_{p}=y_{p}\left(t_{b}\right), y_{b}=y_{0} .
\end{aligned}
$$


The solutions to the above are given below:

$$
\eta=\left(\frac{a+1}{a}\right) e^{a \tau}-1 / a
$$

for $0 \leq \tau \leq t_{b} / t_{i g}$ where $\tau=t / t_{i g}, \eta=y_{p} / y_{0}, a=k_{f} \dot{Q}^{\prime \prime}-1$ and $y_{0}=k_{f} \dot{Q}_{0}^{\prime}$. This assumes that the initial pyrolysis length, $y_{0}$, is determined by the height of the ignition flame.

For $\tau>\left(t_{b} / t_{i g}\right) \equiv \tau_{b}$. Eqns. (4) and (7) are subtracted and solved to yield

$$
\psi=\frac{y_{p}-y_{b}}{y_{0}}=c e^{b\left(\tau-\tau_{b}\right)}
$$

where $\mathrm{b}=\mathrm{a}-1 / \tau_{\mathrm{b}}$

and $\quad c=\left(\frac{a+1}{a}\right)\left[e^{a \tau_{b}}-1\right]$.

From Eqn. (7) it follows that $\eta_{b}=y_{b} / y_{0}$ is given by

$$
\eta_{b}=1+\frac{c}{b \tau_{b}}\left(e^{b\left(r-\tau_{b}\right)}-1\right)
$$

The parameters $a$ and $b$ must be greater than zero in order for the upward fire spread to accelerate. For values less than zero, the spread will eventually stop. This bimodal behavior is a distinct characteristic of upward flame spread which is conditional on the form of Eqn. (6). This clearly shows the role of the energy release rate per unit area and its duration in time, i.e., $\dot{Q}^{n}$ and $t_{b}$.

Opposed flow solution:

From the LIFT procedure $[2,6]$ the governing equation for the pyrolysis position is

$$
\frac{\mathrm{dx}_{\mathrm{p}}}{\mathrm{dt}}=\frac{\Phi}{\mathrm{k} \rho \mathrm{c}\left(\mathrm{T}_{\mathrm{ig}}-\mathrm{T}_{\mathrm{s}}\right)^{2}} \text { for } \mathrm{T}_{\mathrm{s}} \geq \mathrm{T}_{\mathrm{s}, \min } .
$$

This can be rewritten as

$$
\frac{d x_{p}}{d t}=\frac{\frac{\pi}{4\left(q_{f}^{\prime}\right)^{2}}}{t_{i g}}
$$

The dimensionless solution $\xi \equiv \mathrm{x}_{\mathrm{p}} / \mathrm{x}_{0}$ follows as

$$
\xi=\beta r+1
$$

where

$$
\beta=\frac{\pi \Phi \mathrm{x}_{0}}{4\left(\mathrm{q}_{\mathrm{f}}^{\prime}\right)^{2}}
$$


The burnout solution analogously follows from Eqn. (7), i.e.

$$
\frac{d x_{b}}{d t}=\frac{x_{p}-x_{b}}{t_{b}},
$$

and it can be shown that $\xi_{\mathrm{b}}=\mathrm{x}_{\mathrm{b}} / \mathrm{x}_{0}$ is given by

$$
\xi_{\mathrm{b}}=\beta\left(\tau-\tau_{\mathrm{b}}\right)+1, \tau \geq \tau_{\mathrm{b}} .
$$

This completes the solution. These equations will now be applied to specific applications. For each case we shall appropriately apply the equations by accounting for the effects of geometry and thermal feedback as a parameter. For example, a corner wall and ceiling fire will be considered as an extended vertical wall representative of the actual upward and wall ceiling jet region plus a quadrant of a circular ceiling.

To review, the procedure for implementing this solution is as follows:

1. Assemble material data namely, $\bar{Q} ", t_{i_{g}}, t_{b}, \Phi$ and $T_{s, m i n}$.

2. Prescribe the ignition source, $\dot{Q}_{0}^{\prime}$.

3. Since no room fire model is coupled to this analysis, one must set $\mathrm{T}_{\mathrm{s}}$ to a value representative of the particular room configuration.

4. Compute the pyrolysis area $A_{p}$ for the surface configuration using the formulas for $x_{p}$ and $y_{p}$.

5. Compute the fire product output "rate, e.g. rate of any energy release, by multiplying $A_{p}$ by $\dot{Q}$.

\section{APPLICATIONS}

Several applications of the analysis will be presented for cases where scenario results for total energy release exist along with a complete set of fire property data.

\subsection{Full Scale Room - Corner Tests}

A series of full scale room lining fire tests were performed at the Swedish National Testing Institute, Borás, Sweden [10]. The test scenario consisted of lining the walls and ceiling of the room $(2.43 \mathrm{~m}$ by $3.66 \mathrm{~m}$ by $2.43 \mathrm{~m}$ in height with an opening $2 \mathrm{~m}$ by $0.9 \mathrm{~m}$ ) with a given material. A $0.17 \mathrm{~m}$ by 0.17 $\mathrm{m}$ sand burner was placed in the corner of the full scale room. Initially a $100 \mathrm{~kW}$ fire was allowed to burn in the corner. If this fire did not cause flashover in 10 minutes, then the burner output was increased to $300 \mathrm{~kW}$.

Small scale fire test data were obtained by other researchers for the materials used in the Borás study $[5,11,12]$ and were used to develop Table 1. These values are used for the model inputs. In the calculations, ceiling fire spread is accounted for by having the ceiling ignite when the pyrolysis front 
reaches the ceiling. The ceiling spread follows the wind-aided spread along the wall ceiling interface. Thus, the pyrolyzing ceiling area is given as the quadrant of the ceiling with the radius equal to the distance from the corner to the wall ceiling interface pyrolyzing front. Lateral spread was deemed to occur only when the wall surface temperature is at the material's $\mathrm{T}_{\mathrm{s}, \mathrm{min}}$ or greater. The model was run with $T_{s}$ at $25^{\circ} \mathrm{C}$ and $80^{\circ} \mathrm{C}$. While at the start of the experiment the surface temperature is uniform (approximately $25^{\circ} \mathrm{C}$ ) throughout, allowing $\mathrm{T}_{\mathrm{s}}$ to be an input parameter shows the sensitivity to feedback and the effects which increased lateral spread has on the results. This is justified because, while early on in the test $T_{s}$ of $25^{\circ} \mathrm{C}$ is more representative of the room conditions, the upper layer temperature is always increasing and radiative feedback is raising wall and ceiling temperatures. We selected burner flame heights $\left(y_{0}\right)$ of $1.3 \mathrm{~m}$ and $2.1 \mathrm{~m}$ for the 100 and 300 $\mathrm{kW}$ settings. We determined $y_{0}$ values from an axisymmetric fire plume correlation realizing that corner flames would be taller and ignoring ceiling interaction. For cases that stopped propagating before 10 minutes, the analysis was restarted at $t=600 \mathrm{~s}$ from a new origin at $y_{b}(600 \mathrm{~s})$. If $y_{b}(600$ $\mathrm{s})$ is greater than $2.1 \mathrm{~m}$, the ignitor flame height, we arbitrarily selected $0.3 \mathrm{~m}$ as a new $y_{0}$ in order to initiate spread again. Also for $t>600 \mathrm{~s}$, we selected $T_{s}=250^{\circ} \mathrm{C}$ based on the maximum gas temperatures measured [10]. Model predictions and experimental results for the time to a 1 MW fire are given in Table 2. Figure 3 shows the experimental rate of heat release as a function of time (solid curves) and model calculations (dashed curves) with $T_{s}$ $=80^{\circ} \mathrm{C}$ for three of the materials. Appendix A contains plots of experimental rate of heat release and model calculations for all 13 materials. The results are comparable to those of Karlsson (who only considered 6 of the materials) [5], but appear to be distinctly better than the results of Wickström and Göransson [3].

\subsection{PMMA Room Wall Test}

A PMMA wall fire test was performed at NIST [13]. The wall opposite the doorway of an enclosure of roughly the same dimension as the Boras room was lined with $12.7 \mathrm{~mm}$ thick clear PMMA, and a small line burner $0.3 \mathrm{~m}$ wide was placed at floor level in the center of the wall. The igniter flame height was nominally $0.15 \mathrm{~m}$. The pyrolysis area as a function of time was recorded from video records and imbedded thermocouples. Initially, the fire spreads up the wall, and across the wall-ceiling interface (ceiling jet). This mode of spread is characterized as wind-aided spread. As this is occurring, lateral spread is extending the initial pyrolyzing width of $0.3 \mathrm{~m}$. Appendix $B$ shows the measured surface temperatures at different position and the estimated pyrolysis area.

The model input values for this PMMA wall fire are burning rates of 6,7 , and $8 \mathrm{~g} / \mathrm{m}^{2} \mathrm{~s}$ (multiplied by $25 \mathrm{~kJ} / \mathrm{g}$ for rate of heat release), $160 \mathrm{~s}$ for $t_{i, 8}$ (this assumes a value of $380^{\circ} \mathrm{C}$ for $\mathrm{T}_{i g}, 1.02\left(\mathrm{~kW} / \mathrm{m}^{2} \mathrm{~K}\right)^{2} \mathrm{~s}$ for $\mathrm{k} \rho \mathrm{c}$, and $\dot{q}_{f}$ of 25 $\left.\mathrm{kW} / \mathrm{m}^{2}\right), t_{b}$ of $1000 \mathrm{~s}$, and $\Phi$ of $14.4 \mathrm{~kW}^{2} / \mathrm{m}^{3}$. The minimum temperature for lateral spread is approximately $25^{\circ} \mathrm{C}$ for this material. With these input values, the pyrolysis area is calculated as a function of time for the three different burning rates. These burning rates are representative of unenhanced wall burning rates which would be applicable before significant thermal feedback occurs. The results are shown in Figure 4. The model results with 
input burning rates of 6 and $8 \mathrm{~g} / \mathrm{m}^{2} \mathrm{~s}$ bound the measured pyrolysis area while 7 $\mathrm{g} / \mathrm{m}^{2} \mathrm{~s}$ compares well up to $700 \mathrm{~s}$. The calculated areas start to level off after the pyrolysis front reaches the ends of the wall (laterally) at the wall-ceiling interface. The experimental results show a rapid increase in pyrolysis area due to a fast downward spread. This is due to the thermal feedback of the hot layer increasing the surface temperature of the wall, thus increasing downward spread. This feedback is not explicitly accounted for in the model, therefore, we do not expect to match the experimental results at long times. Also we have used burning rates for PMMA associated with no external irradiance. This is in contrast to our use of Cone Calorimeter data at irradiance levels of $25 \mathrm{~kW} / \mathrm{m}^{2}$ and higher for corner fire tests.

\subsection{Textile Wall Covering Room Tests}

A series of textile wall fire tests was performed by the U.C., Berkeley for the American Textile Manufactures Institute [14]. In these tests, 0.31 m (1 $\mathrm{ft}$ ) and $0.62 \mathrm{~m}(2 \mathrm{ft}$ ) wide strips of different textile wall covering materials were applied to a corner section and the wall portion of the wall-ceiling interface of a room with roughly the same dimensions of the room used in the tests above. A $0.31 \mathrm{~m}$ by $0.31 \mathrm{~m}$ sand burner was placed in the material lined corner approximately $10 \mathrm{~cm}$ from the walls. A small $40 \mathrm{~kW}$ fire was allowed to burn in the corner for 5 minutes, then the burner output was increased to 150 $\mathrm{kW}$. The position of the burner and the size of the small $40 \mathrm{~kW}$ fire was such that in most cases it did not cause the textile material to ignite, but shortly after the burner output was increased to $150 \mathrm{~kW}$, all wall lining materials ignited. The rate of heat release was obtained during each test. The data for input into the model is given by Harkleroad [15]. Here lateral spread was not included in the calculations since lateral spread is not expected with the $0.31 \mathrm{~m}$ wide strips anyway. It appears from the experimental results that the $40 \mathrm{~kW}$ fire only served to preheat the room, therefore we picked an initial surface temperature of $100^{\circ} \mathrm{C}$ based on the maximum gas temperatures measured during this preheating time. In the experiments, there appears to be very little ignition delay of the materials after the burner output is increased to $150 \mathrm{~kW}$. This is due to the preheating by the small 40 $\mathrm{kW}$ fire, and the high heat flux from the $150 \mathrm{~kW}$ fire. Table 3 shows the experimental and calculated results. By examining the $0.31 \mathrm{~m}$ and $0.62 \mathrm{~m}$ wide strip results, it appears in some cases lateral spread is significant. The model calculations were performed for the $0.31 \mathrm{~m}$ wide strip cases using Cone Calorimeter data at external irradiances of 30 and $50 \mathrm{~kW} / \mathrm{m}^{2}$. Ignition delay times for each of the materials were calculated from Eq. (5). For this calculation, we assumed $\mathrm{T}_{\mathrm{s}}=100^{\circ} \mathrm{C}$ and $\dot{\mathrm{q}}_{\mathrm{f}}^{\prime \prime}=60 \mathrm{~kW} / \mathrm{m}^{2}$ which represents the high heat flux produced by the ignitor [16], and added this calculated ignition time to the model calculated time to reach the peak rate of heat release. The peak heat release rate and the time interval from the start of the $150 \mathrm{~kW}$ fire for the $0.31 \mathrm{~m}$ strips compare favorably with the calculations. After the peak heat release was obtained a rapid decay was observed experimentally for most cases, this was predicted well by the model. 


\section{CONCLUDING RFMARKS}

We have presented evidence that an engineering approach utilizing "fire property" data from test methods can satisfactorily predict full scale energy release of room lining fires. The fire properties used are not necessarily fundamental engineering data, but the analysis does not preclude the use of such properties. Consequently, the choice of the fire properties used is somewhat arbitrary until the fire heat transfer conditions can be related to the test method irradiance levels. Also the model used to make the predictions, although yielding reasonably satisfactory results, should be refined and improved. Nevertheless, the framework presented should serve as a basis for these improvements and might be used now to more rationally assess the fire growth hazard of lining materials.

\section{Acknowledgement}

We are grateful to Mr. Richard Gottwald and the Society of Plastics Industries for partial support in developing this study. 


\section{Nonenclature}

A area

a dimensionless parameter, Eq. (9)

b dimensionless parameter, Eq. (10)

c dimensionless parameter, Eq. (10)

$\mathrm{k} \rho \mathrm{c}$ thermal inertia (thermal conductivity $\mathrm{x}$ density $\mathrm{x}$ specific heat)

$\mathrm{k}_{\mathrm{f}} \quad$ constant, $0.01 \mathrm{~m}^{2} / \mathrm{kW}, \mathrm{Eq}$. (6)

q heat transfer

Q energy

$t$ time

$t$ temperature

$x$ opposed flow coordinate direction

$y$ wind-aided coordinate direction

$\beta$ dimensionless parameter, Eq. (14)

$\tau$ dimensionless time, $t / t_{b}$

$\xi$ dimensionless pyrolysis position, $x_{p} / x_{0}$

$\xi_{\mathrm{b}}$ dimensionless burnout position, $\mathrm{x}_{\mathrm{b}} / \mathrm{x}_{\mathrm{o}}$

$\eta \quad$ dimensionless pyrolysis position, $y_{p} / y_{0}$

$\eta_{\mathrm{b}}$ dimensionless burnout position, $\mathrm{y}_{\mathrm{b}} / \mathrm{y}_{\mathrm{o}}$

$\Phi$ flame heating parameter, Eq. (12)

Subscripts:

b burnout

f flame

ig ignition

o initial

$\mathrm{p}$ pyrolysis

Superscripts :
(') average
(·) per unit time
( )' per unit width
( )" per unit area 


\section{REFERENCES}

1. Standard Test Method for Heat and Visible Smoke Release Rates for Materials and Products Using an Oxygen Consumption Calorimeter, (ASTM E 1354), Amer. Soc. for Testing and Materials, Philadelphia.

2. Quintiere, J.G. and Harkleroad, M., "New Concepts for Measuring Flame Spread Properties", pp. 239-267 in Fire Safety Science and Engineering (ASTM STP 882), Amer.Soc. for Testing and Materials, Philadelphia, PA, 1985.

3. Wickström, U., Göransson, U., "Prediction of Heat Release Rates of Surface Materials in Large-Scale Fire Tests Based on Cone Calorimeter Results", ASTM Journal of Testing and Evaluation, Vol. 15, No. 6, 1987.

4. Östman, B., and Nussbaum, R., "Correlation Between Small-Scale Rate of Heat Release and Full-Scale Room Flashover for Surface Linings", pp. 823832. in Fire Safety Science Proc. of the Second International Symposium (1988), Hemisphere Publishing, New York (1989).

5. Kaxlsson, B., "Room Fires and Combustible Linings", Dept. of Fire Safety Engineering, Lund Institute of Science and Technology, Report, Lund, 1989.

6. Standard Method for Determining Material Ignition and Flame Spread Properties, (ASTM E 1321), Amer. Soc. for Testing and Materials, Philadelphia.

7. Saito, F., Williams, F.A., Wichman, I.S. and Quintiere, J.G., "Upward Turbulent Flame Spread on Wood Under External Radiation", Jolinal of heat Transfer, pp. 438-445, Vol. 111, May 1989.

8. Quintiere, J.G., "The Application of Flame Spread Theory to Predict Material Performance", Journal of Research of the Nat. Bur. of Stds., pp. 61-70, Vol. 93, No. 1, Jan.-Feb. 1988.

9. Quintiere, J.G., Harkleroad, M. and Hasemi, Y., Combustion Science Technology, Vol. 48, 1986.

10. Sundström, B., "Full Scale Fire Testing of Surface Materials", Technical Report SP-RAPP 1986:45, Swedish National Testing Institute, Boràs 1986.

11. Quintiere, J., Harkleroad, M., "New Concepts for Measuring Flame Spread Properties", National Bureau of Standards (U.S.) NBSIR 84-2943, 1984.

12. Tsantaridis, L. and Östman, B., "Smoke, Gas and Heat Release Data for Building Products in the Cone Calorimeter", TrateknikCentrum, Report I $8903013,1989$.

13. Lee, B., Private Communication, Memo to J. Quintiere, Feb. 18, 1987 , National Institute of Standards and Technology, Gaithersburg, MD. 
14. Fisher, F., MacCracken, B., and Williamson, R., "Room Fire Experiments of Textile Wall Coverings", Fire Research Laboratory, University of California, Berkeley, California, 1986.

15. Harkleroad, M., "Fire Properties Database for Textile Wall Coverings", National Institute of Standards and Technology (U.S.), NISTIR 89 4065, 1989 .

16. Mowrer, F., Private Communications, Univ. of Maryland, July 1990. 
Table 1

Flame Spread and Heat Release Properties of Swedish Fire Test Materials

Material

\begin{tabular}{|c|c|c|c|c|c|c|c|}
\hline $\begin{array}{l}\mathrm{T}_{\mathrm{ig}} \\
\left({ }^{\circ} \mathrm{C}\right)\end{array}$ & $\begin{array}{c}\mathrm{k} \rho \mathrm{c} \\
\left(\mathrm{kW} / \mathrm{m}^{2} \mathrm{~K}\right)^{2} \mathrm{~s}\end{array}$ & $\begin{array}{c}\Phi \\
\left(k W^{2} / \mathrm{m}^{3}\right)\end{array}$ & $\begin{array}{l}T_{s, \text { min }} \\
\left({ }^{\circ} \mathrm{C}\right)\end{array}$ & $\begin{array}{l}\dot{\text { Q }} \\
(\mathrm{kW}) \\
(25\end{array}$ & $\begin{array}{r}t_{b} \\
(s) \\
\left.k W / m^{2}\right)\end{array}$ & $\begin{array}{l}\dot{Q} " \\
(\mathrm{~kW}) \\
(50\end{array}$ & $\begin{array}{r}t_{b} \\
(s) \\
\left.\mathrm{kW} / \mathrm{m}^{2}\right)\end{array}$ \\
\hline 405 & 0.626 & 8 & 180 & 140 & $>500$ & 200 & $>500$ \\
\hline 381 & 0.229 & 14 & 90 & 120 & $>500$ & 150 & $>300$ \\
\hline
\end{tabular}

Insulating

$361 \quad 0.732$

11

$80 \quad 140>500$

$170>600$

Fiberboard

Wood Pane1

389

0.569

24

155

140

$>200$

160

$>400$

(Spruce)

Melamine Covered

483

0.804

$<1$

435

115

$>400$

Particle Board

Paper Covered

388

0.593

0.5

300

100

40

200

20

Gypsum Board

PVC Covered

410

0.208

25

300

105

20

160

20

Gypsum Board

Textile Covered 406

0.570

9

270

200

30

300

20

Gypsum Board

Textile Covered 391

0.183

6

174

250

30

375

20

Paper Covered

426

0.680

13

250

140

$>500$

$150>500$

Polyure thane

393

0.031

3

105

110

60

180

60

Expanded

482

0.464

$-$

14

380

100

20

- Data were not taken 
Table 2

Time to Achieve a 1 MW Fire for the Swedish Room Tests

Experimental Time

(s)

Material

$$
\begin{array}{ccc} 
& \text { Mode1 Calculations } \\
\text { Irradiance } & \text { Irradiance } & \text { Irradiance } \\
25 \mathrm{~kW} / \mathrm{m}^{2} & 50 \mathrm{~kW} / \mathrm{m}^{2} & 25 \mathrm{~kW} / \mathrm{m}^{2} \\
\left(\mathrm{~T}_{\mathrm{s}}=25^{\circ} \mathrm{C}\right) & \left(\mathrm{T}_{\mathrm{s}}=25^{\circ} \mathrm{C}\right) & \left(\mathrm{T}_{\mathrm{s}}=80^{\circ} \mathrm{C}\right) \\
(\mathrm{s}) & (\mathrm{s}) & (\mathrm{s})
\end{array}
$$
(s)
(s)
(s)

\section{Particle Board}

157

198

143

145

Insulating

59

77

58

55

Fiberboard

131

180

148

125

Fiberboard

131

165

143

117

(Spruce)

Melamine Covered

465

Particle Board

Paper Covered

640

Gypsum Board

PVC Covered

611

Gypsum Board

Textile Covered

639

615

402

Gypsum Board

Textile Covered

Mineral Wool

Paper Covered

Particle Board

Rigid Polyurethane

6

Foam

Expanded

115

632

616

641

619

606

622

Polystyrene

Gypsum Board

- Data were not taken

* Did not Reach 1 MW 
Table 3

Textile Wall Coverings Room Fire Tests

Full Scale Screening Tests

$0.31 \mathrm{~m}$ Strips $0.62 \mathrm{~m}$ Strips

$\dot{\mathrm{Q}}_{\mathrm{p}}$

$(\mathrm{kW})$

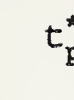

(s)
$\dot{\mathrm{Q}}_{\mathrm{p}}$

$(\mathrm{kW})$

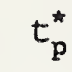

(s)
Model Calculations

Irradiance
$30 \mathrm{~kW} / \mathrm{m}^{2}$

Irradiance $50 \mathrm{~kW} / \mathrm{m}^{2}$

$\dot{\mathrm{Q}}_{\mathrm{p}} \quad \mathrm{t}_{\mathrm{p}}^{*} \quad \dot{\mathrm{Q}}_{\mathrm{p}}$

$(\mathrm{kW})$ (s) (kW) $t_{p}^{*}$

(s)

MATERIAL

\begin{tabular}{|c|c|c|c|c|c|c|c|c|}
\hline $\begin{array}{l}\text { (H) } 858 \text { wool } \\
158 \text { cotton }\end{array}$ & 46 & 30 & 160 & 40 & & & 146 & 46 \\
\hline $\begin{array}{l}\text { (C) } 558 \text { cotton } \\
458 \text { rayon }\end{array}$ & 62 & 30 & 119 & 60 & 137 & 40 & 139 & 37 \\
\hline $\begin{array}{l}\text { (G) } 1008 \\
\text { polyester }\end{array}$ & 83 & 30 & & & 64 & 39 & 56 & 44 \\
\hline $\begin{array}{l}\text { (B) } 1008 \\
\text { polyester }\end{array}$ & 207 & 45 & 298 & 60 & 121 & 46 & 270 & 46 \\
\hline $\begin{array}{l}\text { (Q) } 100 \% \\
\text { polyester }\end{array}$ & 207 & 40 & 480 & 40 & 145 & 50 & 293 & 55 \\
\hline $\begin{array}{l}\text { (Qfr) } 1008 \\
\text { polyester }\end{array}$ & 310 & 40 & & & 157 & 43 & 292 & 59 \\
\hline $\begin{array}{l}\text { (R) } 1008 \\
\text { nylon }\end{array}$ & 587 & 70 & 590 & 70 & 46 & 46 & 416 & 51. \\
\hline $\begin{array}{l}\text { (AA) } 708 \text { acrylic } \\
308 \text { wool }\end{array}$ & 684 & 30 & & & 725 & 109 & 744 & 106 \\
\hline $\begin{array}{l}\text { (PPPF) } \\
\text { polypropylene }\end{array}$ & & & 337 & 50 & 271 & 45 & 450 & 48 \\
\hline
\end{tabular}




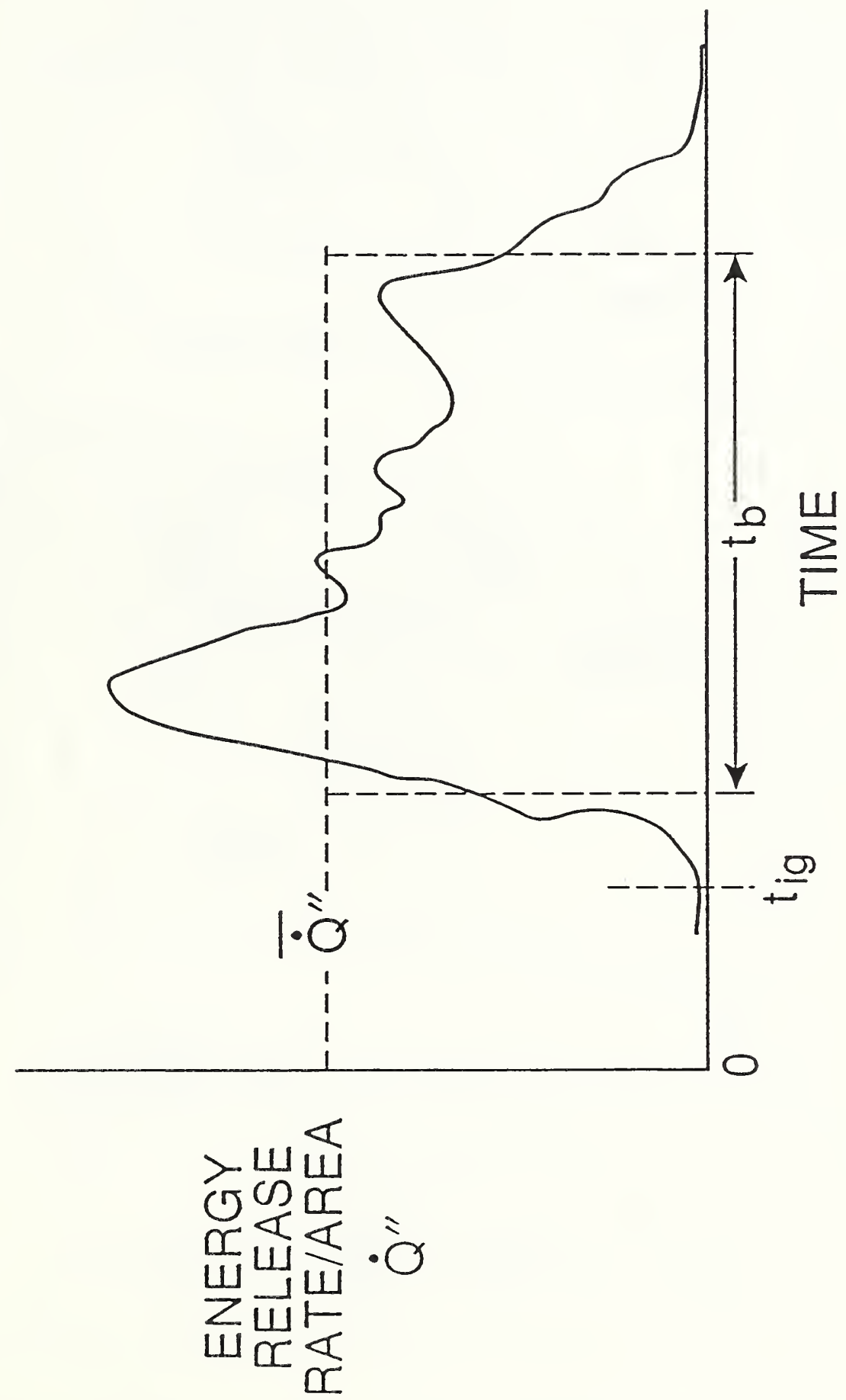

Figure 1. Energy release property data. 
(a)

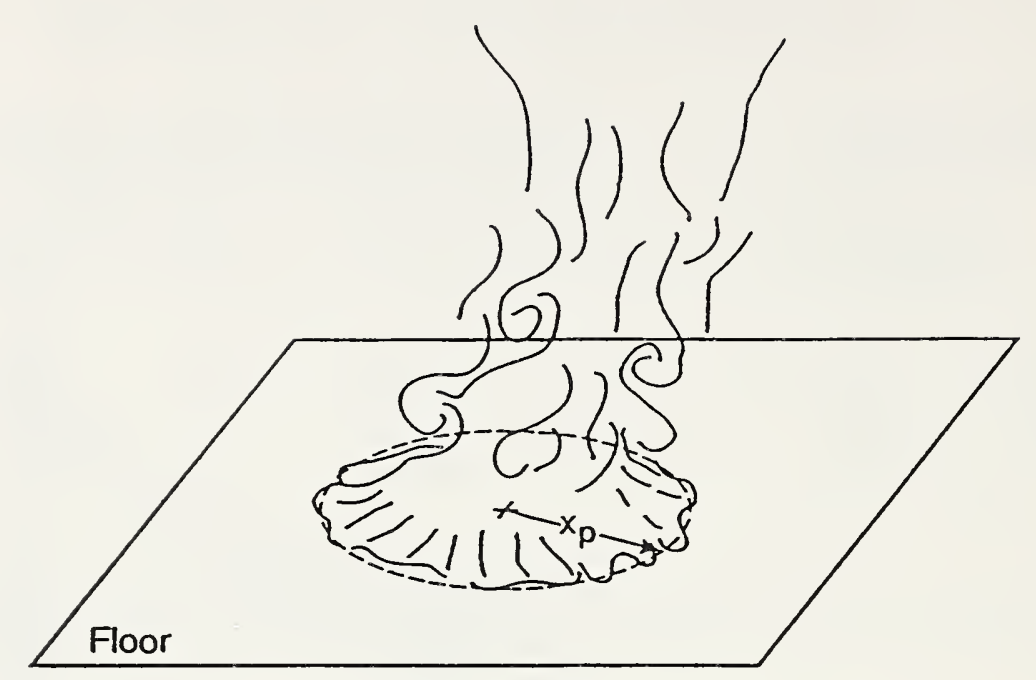

(b)

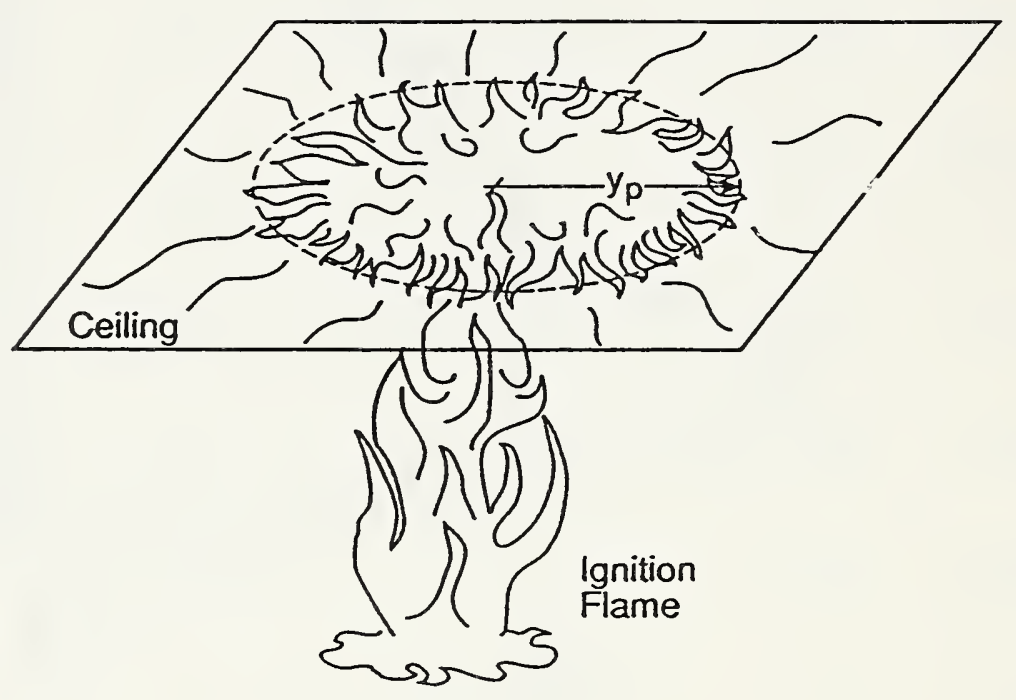

(c)

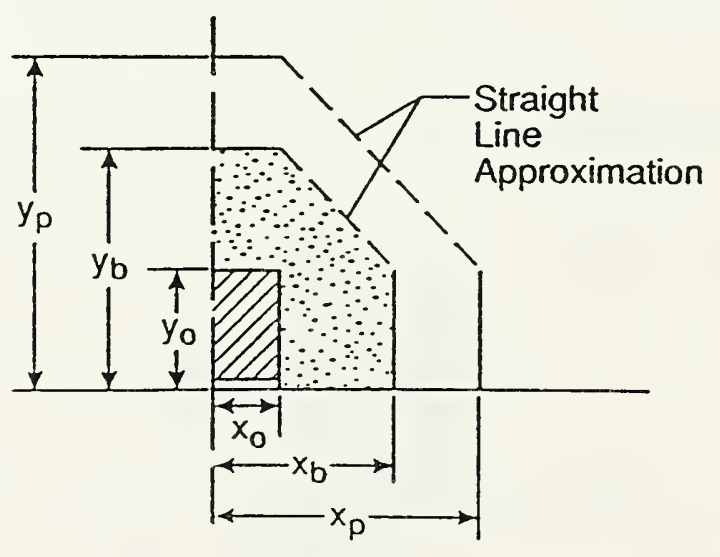

Figure 2. Model floor, ceiling and wall configurations 


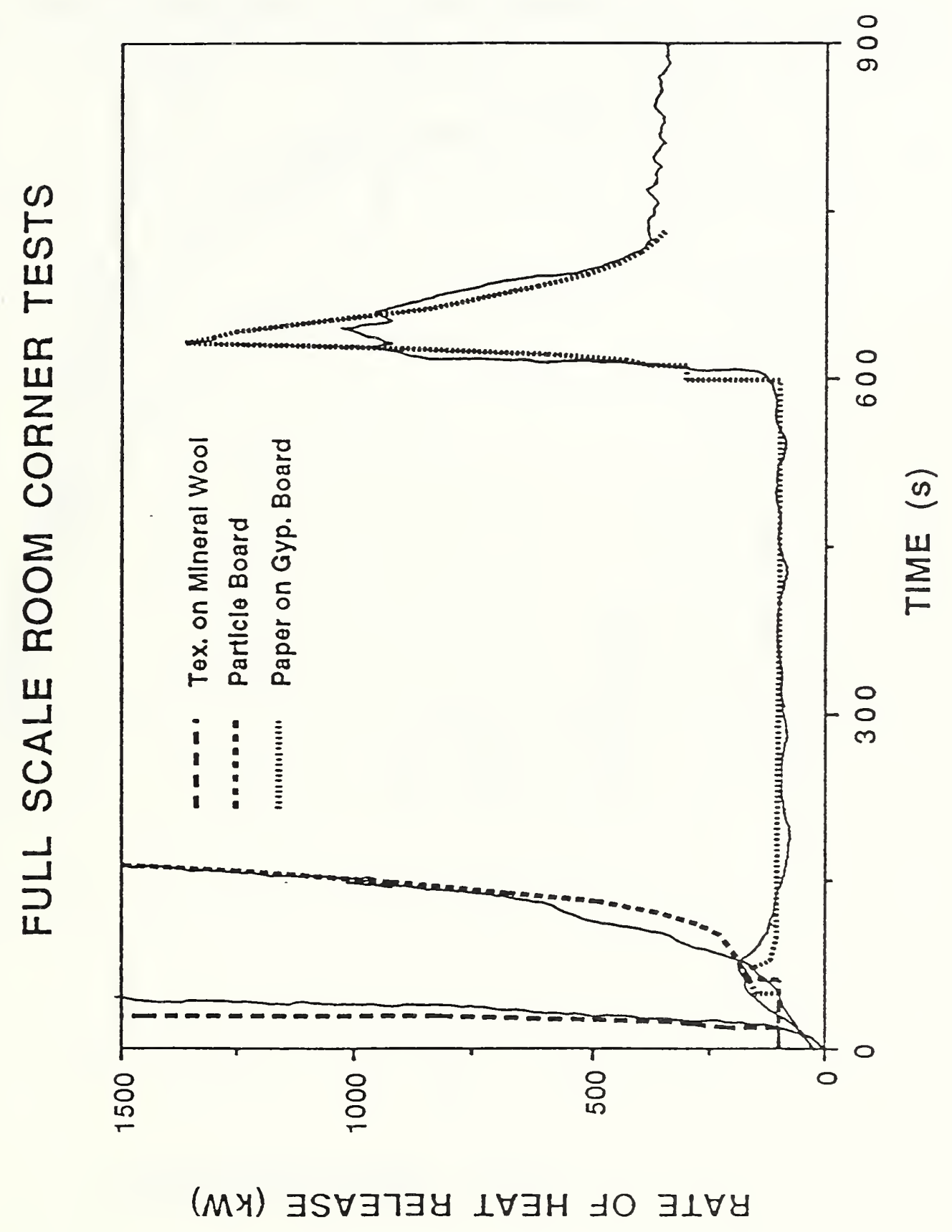

Figure 3. Energy release predictions for the Borâs data 


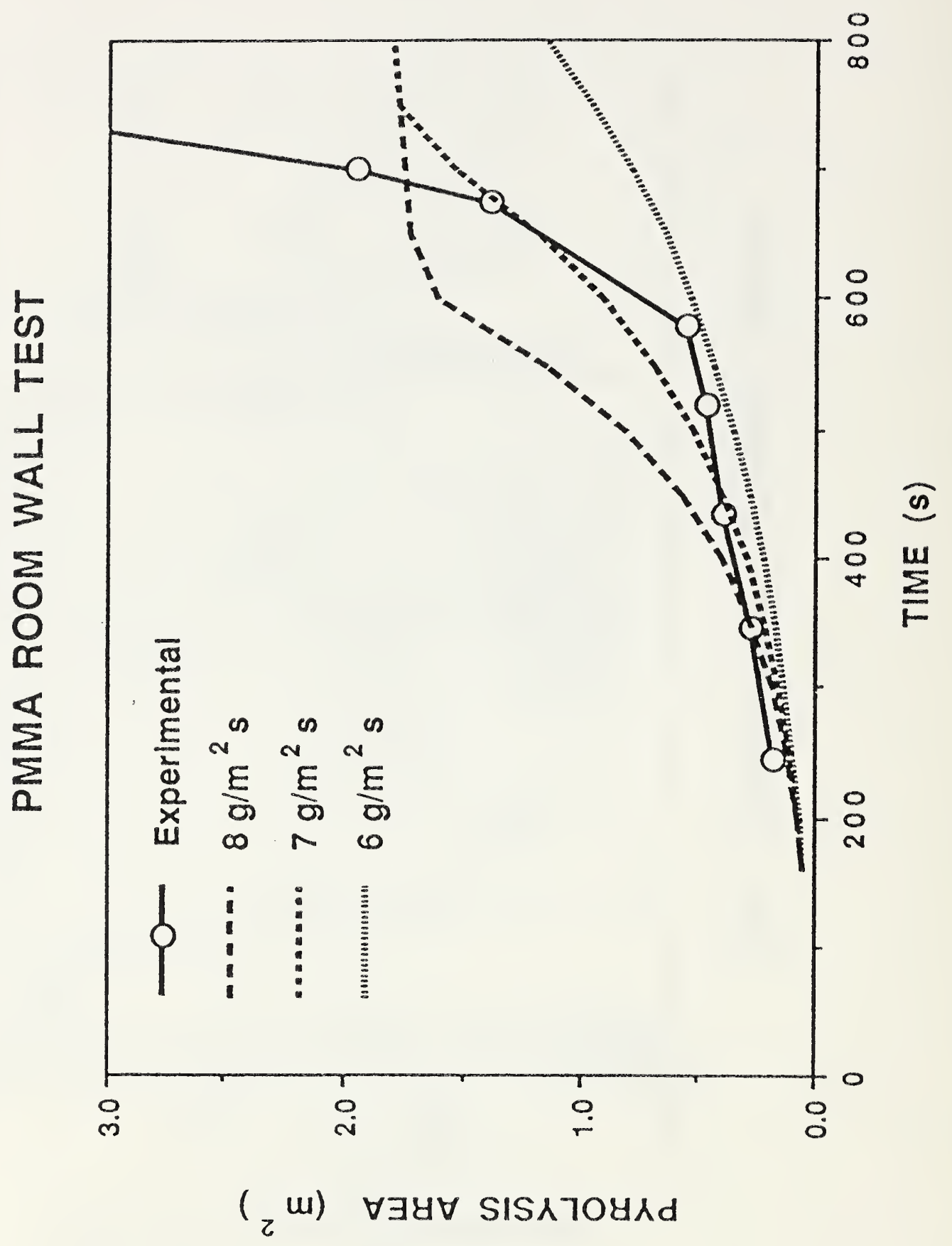

Figure 4. Growth of the pyrolysis area on a PMMA wall 


\section{Appendix A. Full Scale Room-Corner Tests}

The experimental results and model predictions for the twelve materials examined at the Swedish National Testing Institute are shown in figures A-1 to A-12. Model calculations with $\mathrm{T}_{\mathrm{s}}=25^{\circ} \mathrm{C}$ and $80^{\circ} \mathrm{C}$ are both presented. Data From the Cone Calorimeter at an irradiance of $25 \mathrm{~kW} / \mathrm{m}^{2}$ was used for these calculations with the exception of Melamine-faced particle board and Polystyrene where Cone Calorimeter data at an irradiance of $50 \mathrm{~kW} / \mathrm{m}^{2}$ were used. 


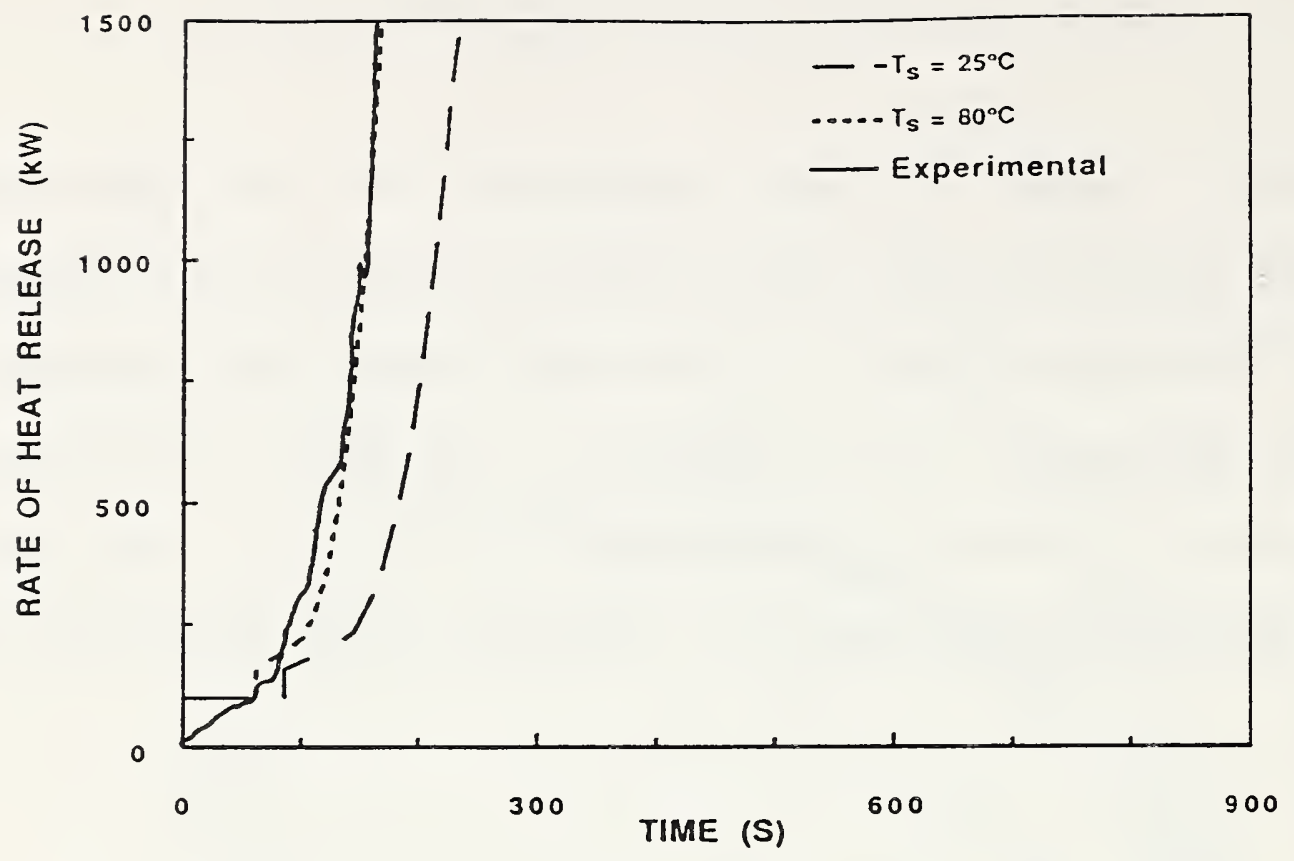

Figure A-1. Rate of heat release vs. time for particle board lined room

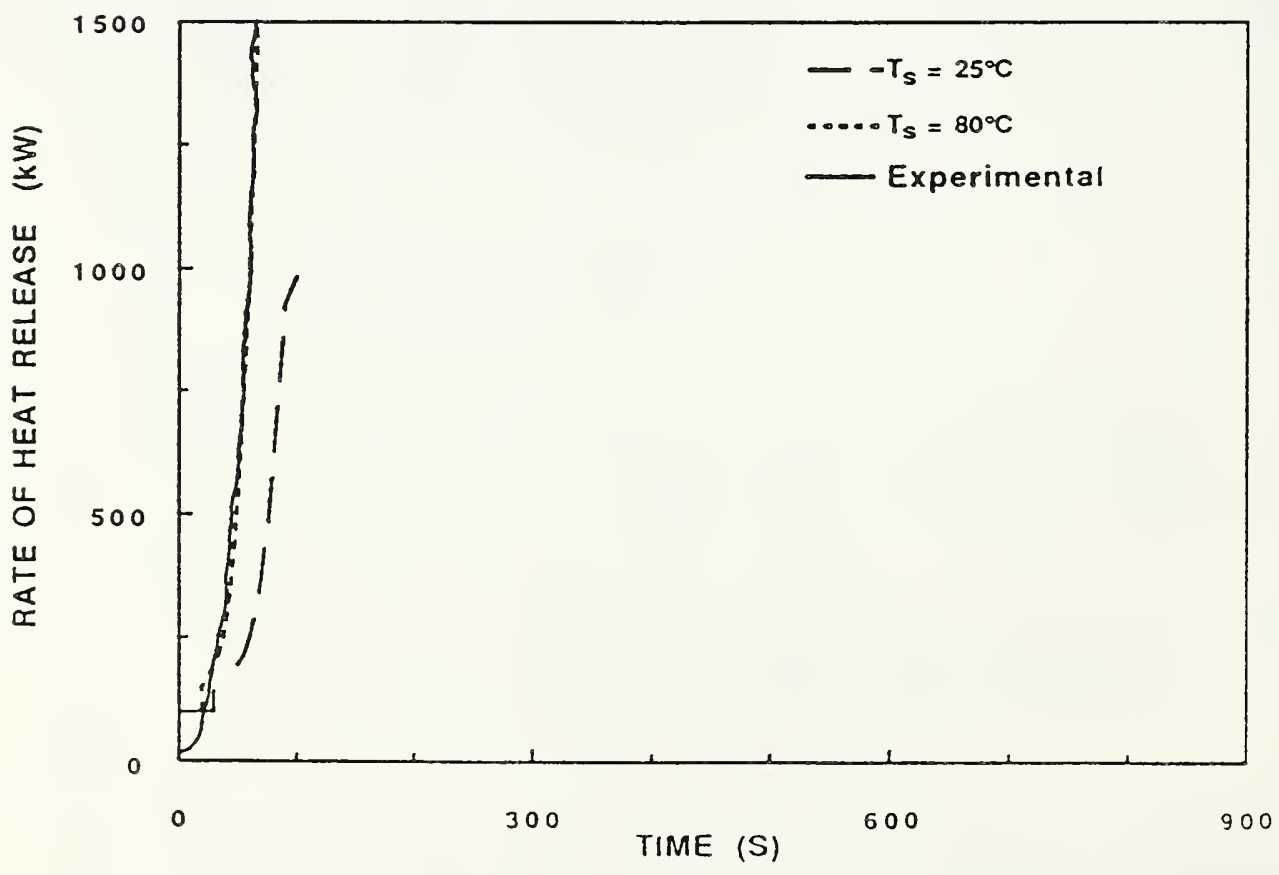

Figure A-2. Rate of heat release vs. time for insulating fiberboard lined room fire 


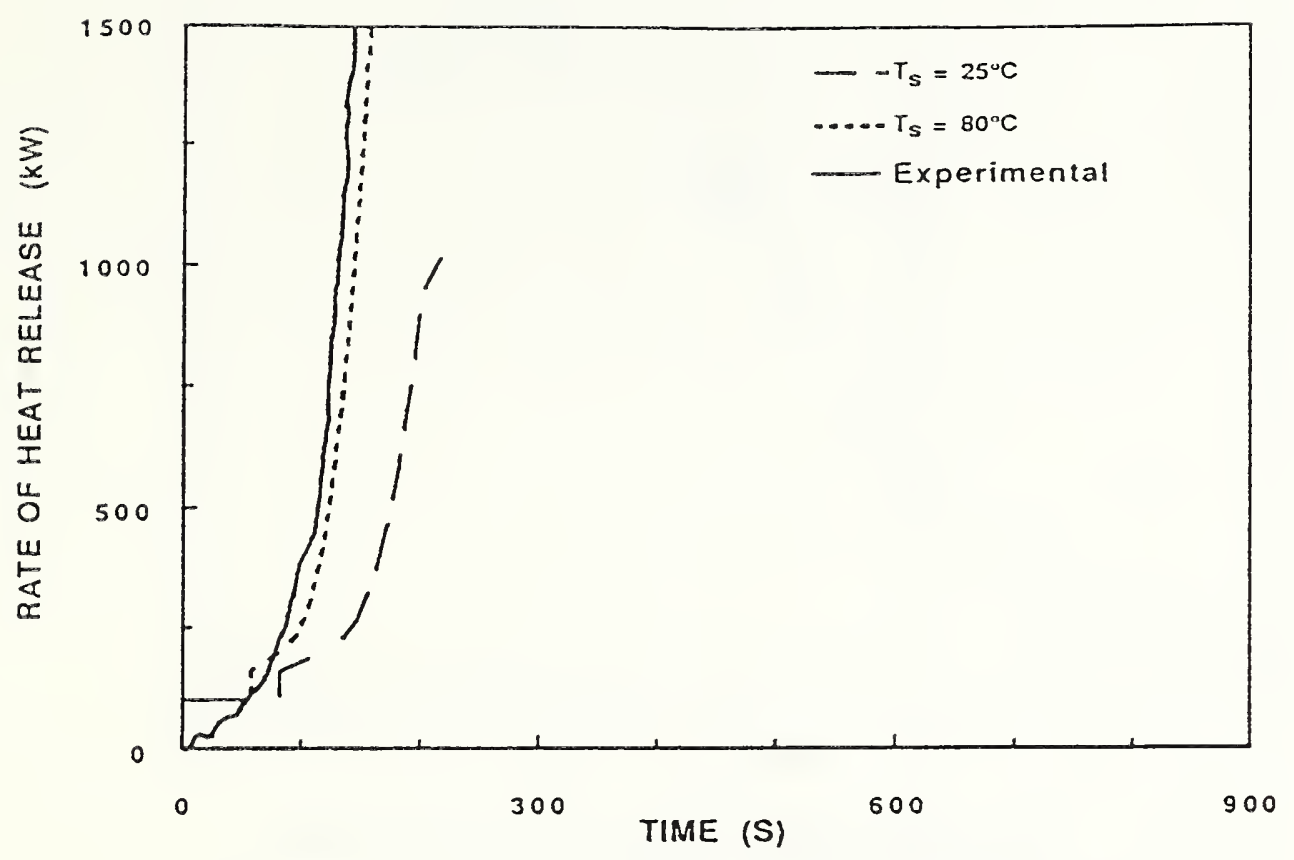

Figure A-3. Rate of heat release vs. time for medium density fiberboard lined room fire.

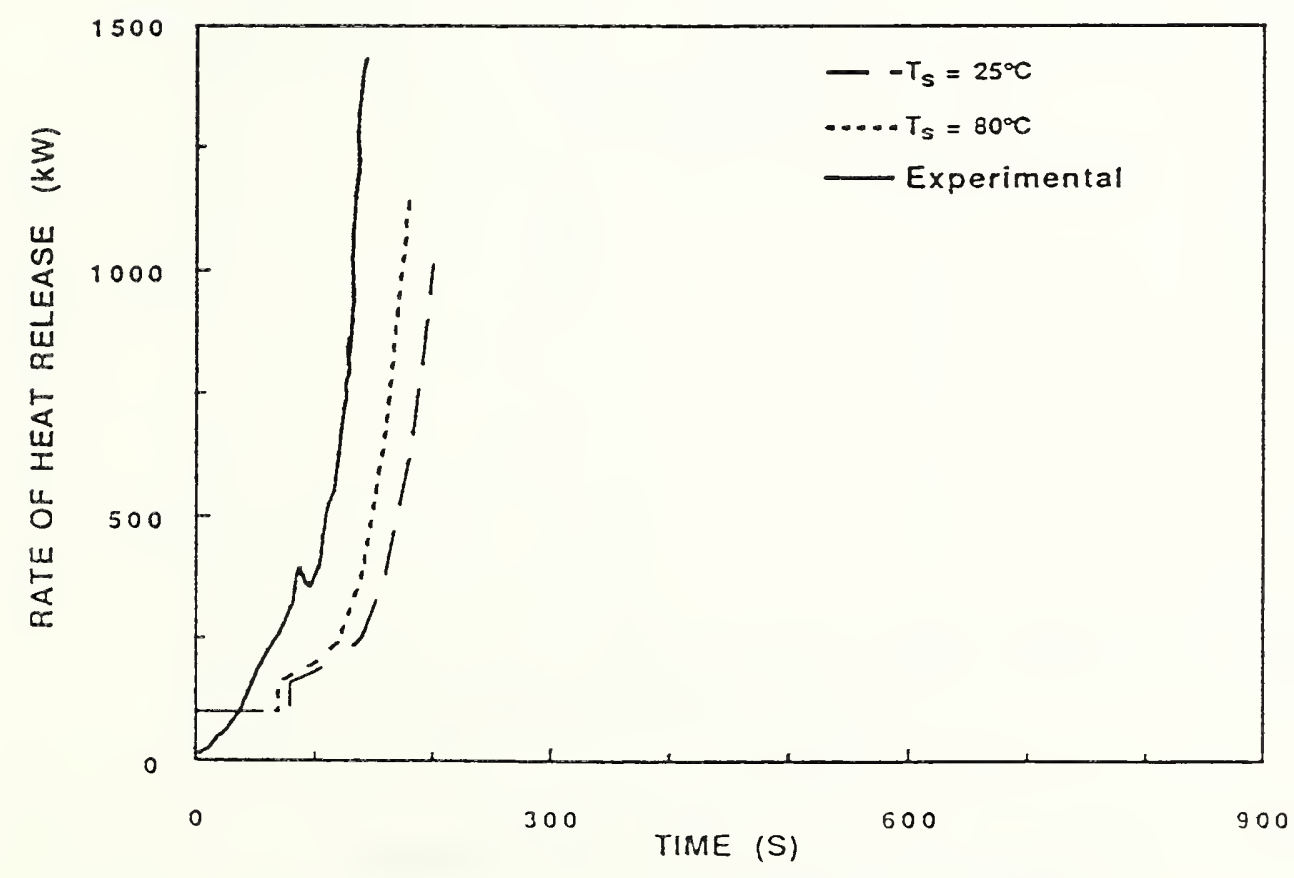

Figure A-4. Rate of heat release vs. time for wood paneling lined room fire. 


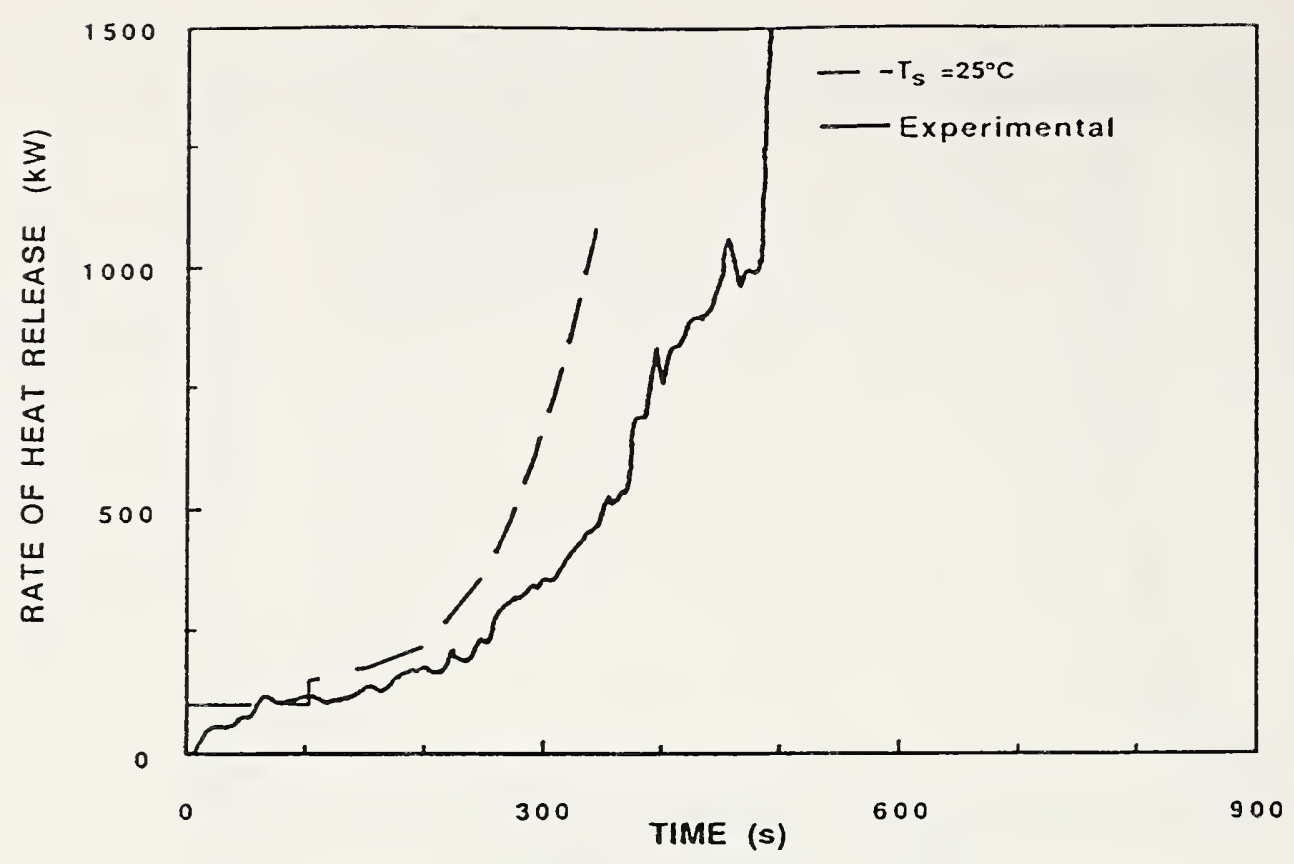

Figure A-5. Rate of heat release vs. time for melarnine faced particle board lined room fire.

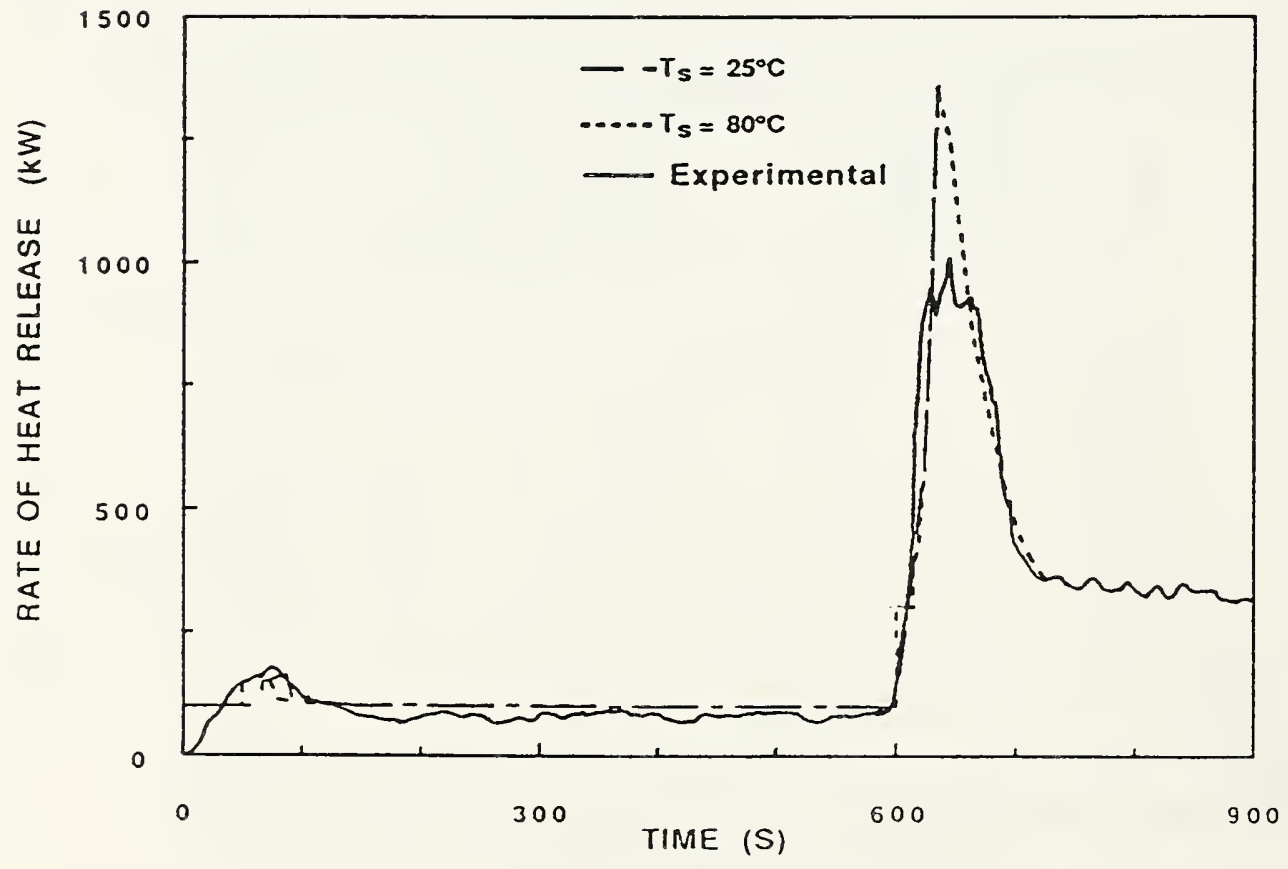

Figure A-6. Rate of heat release vs. lime for paper covered gypsum board room fire. 


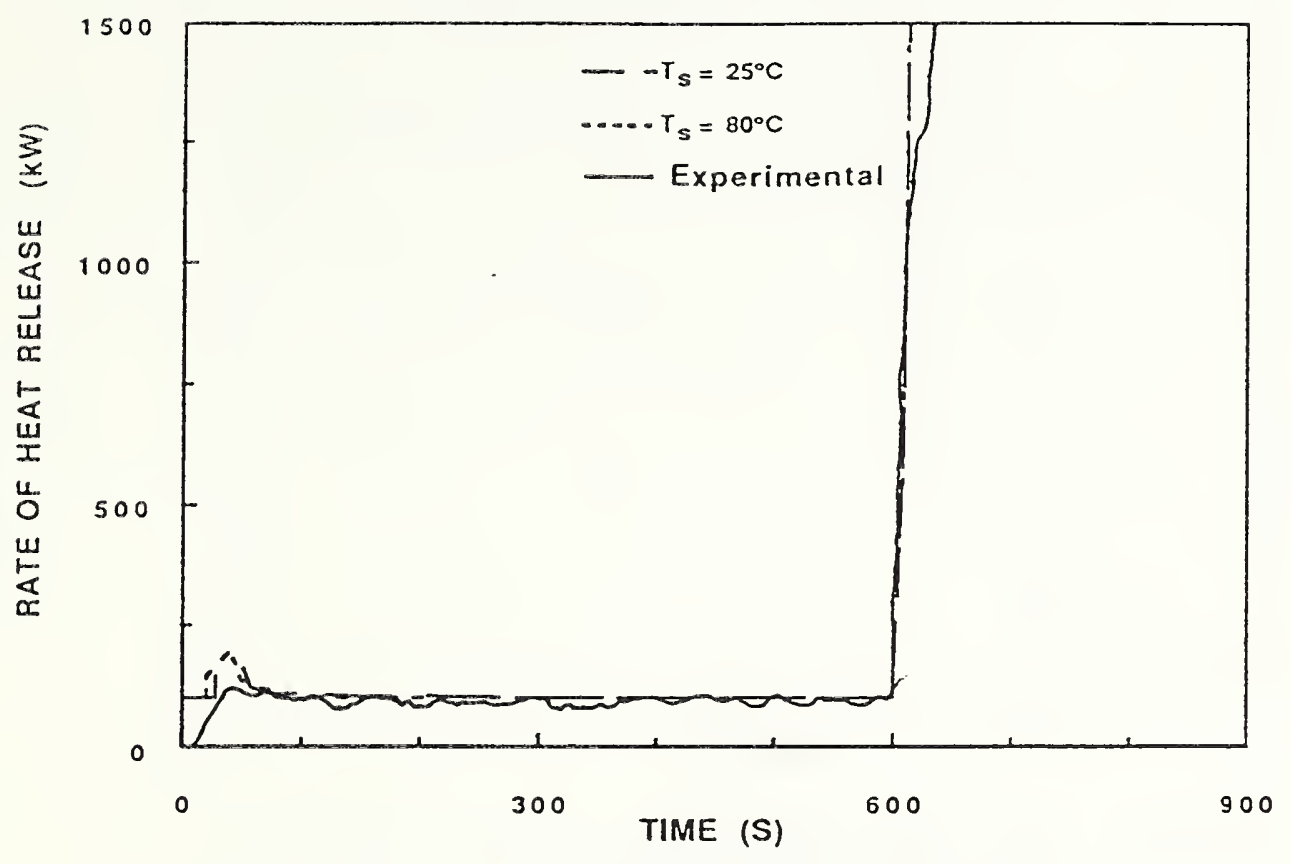

Figure A-7. Rate of heat release vs. time for pvc covered gypsum board room fire.

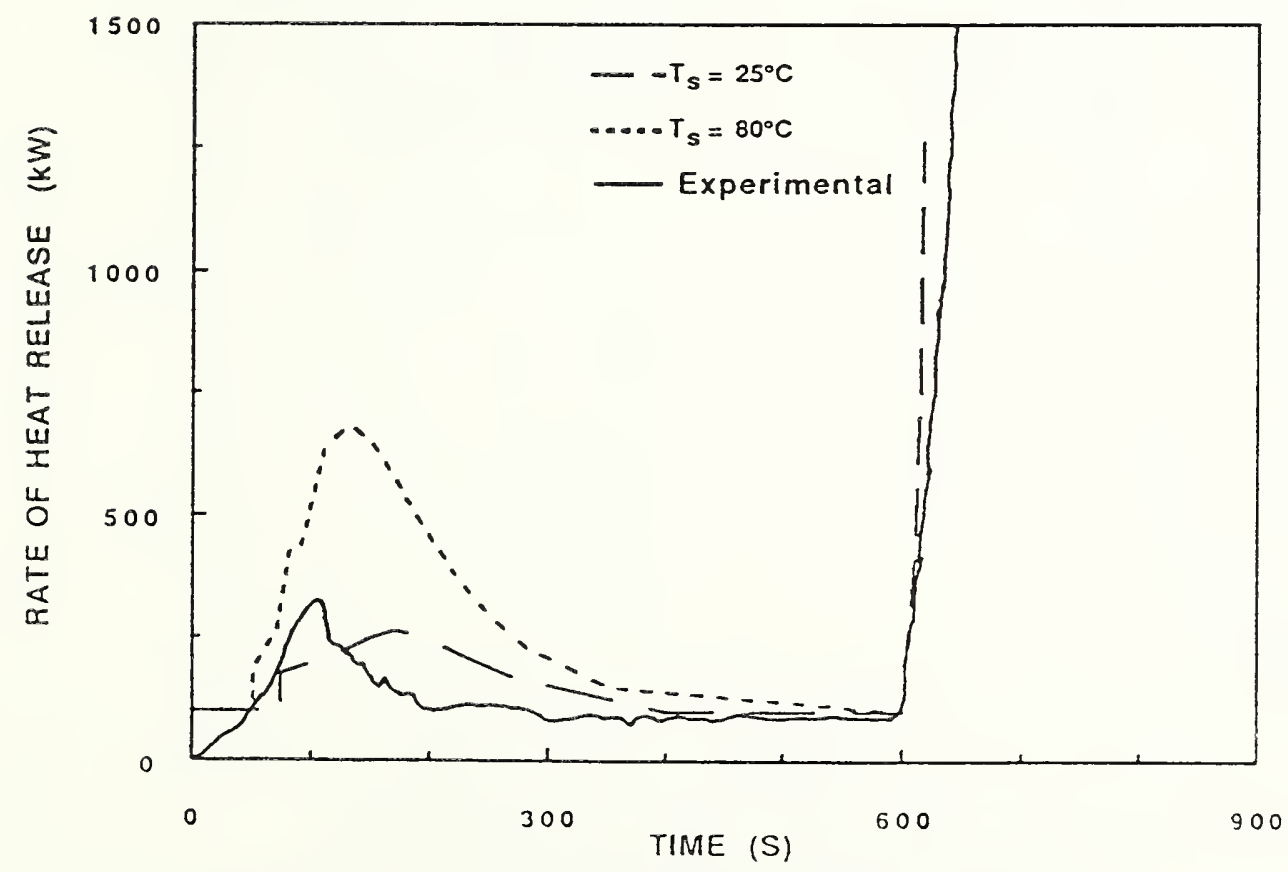

Figure A-8. Rate of heat release vs. time for textile wallcovering on gypsum board lined room fire. 


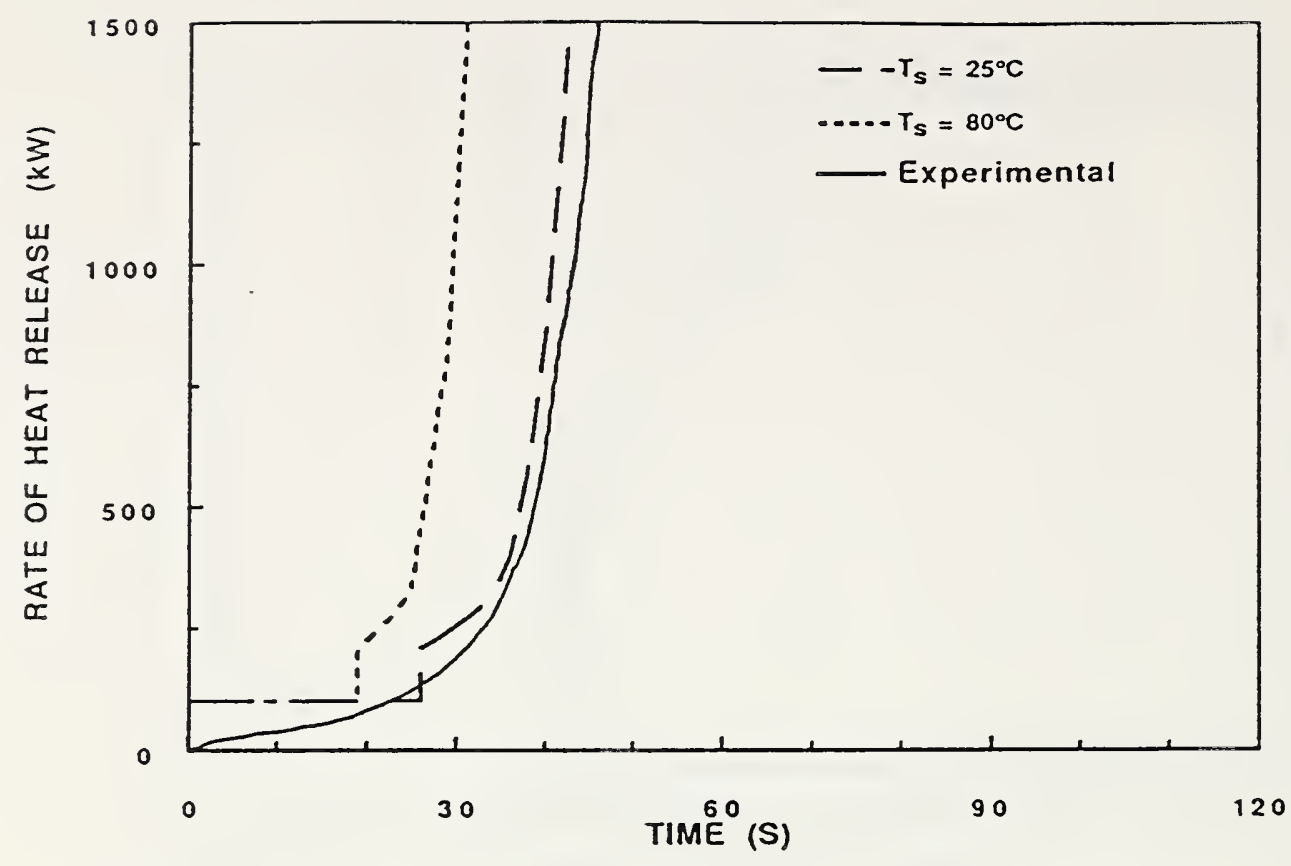

Figure A-9. Rate of heat release vs. time for textile wallcovering on mineral wool lined room fire.

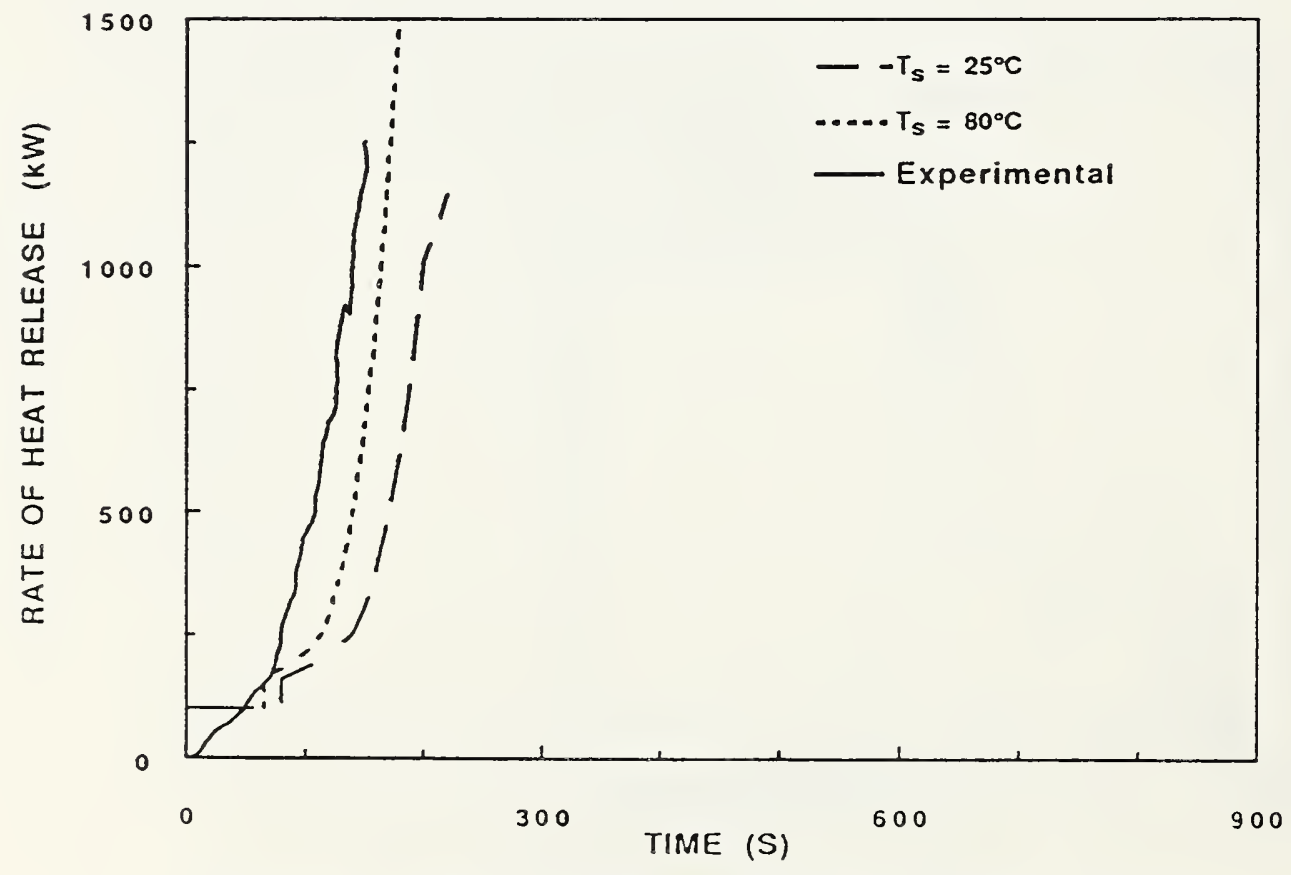

Figure A-10. Rate of heat release vs. time for paper covered particle board lined room fire. 


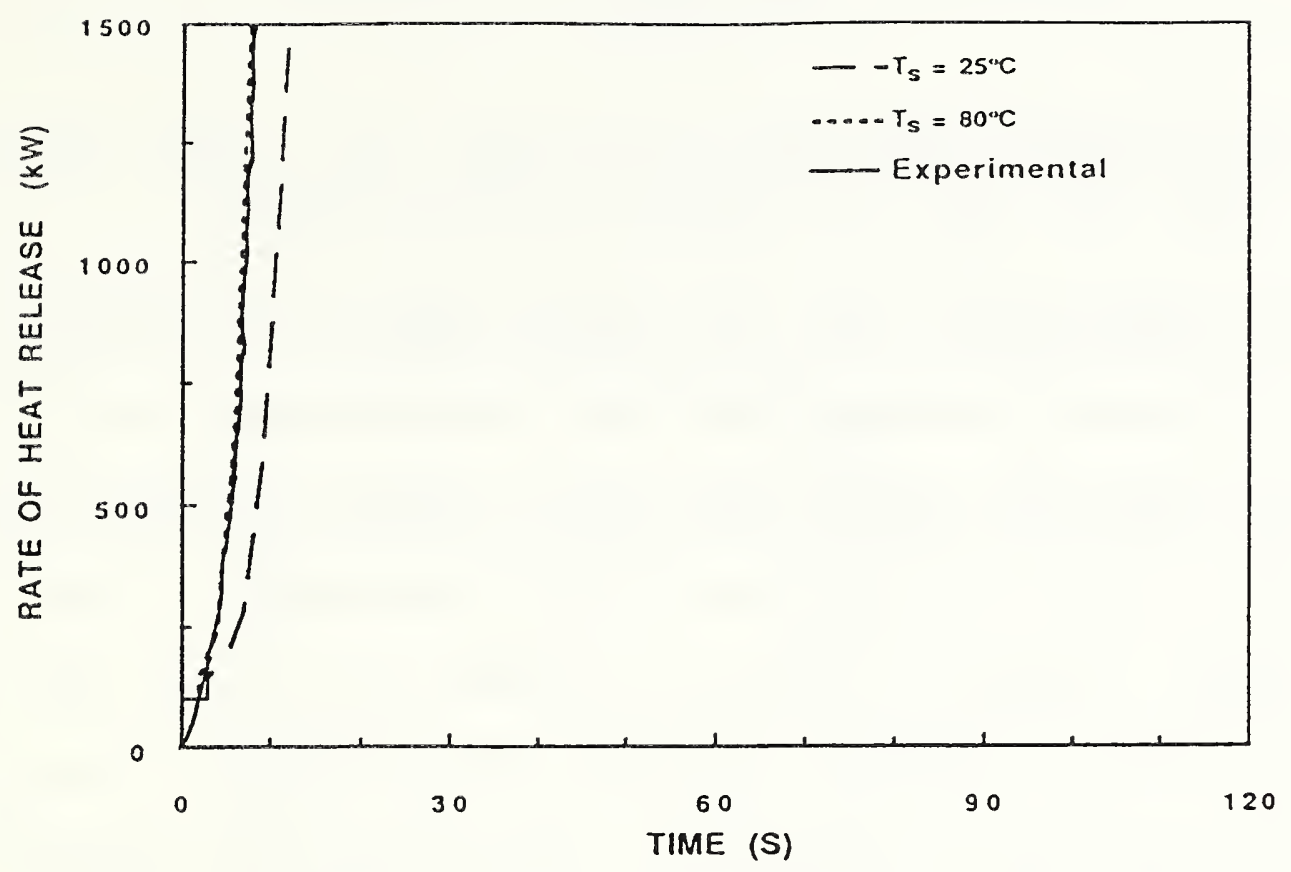

Figure A-11. Rate of heat release vs. time for rigid polyurethane foam lined room fire.

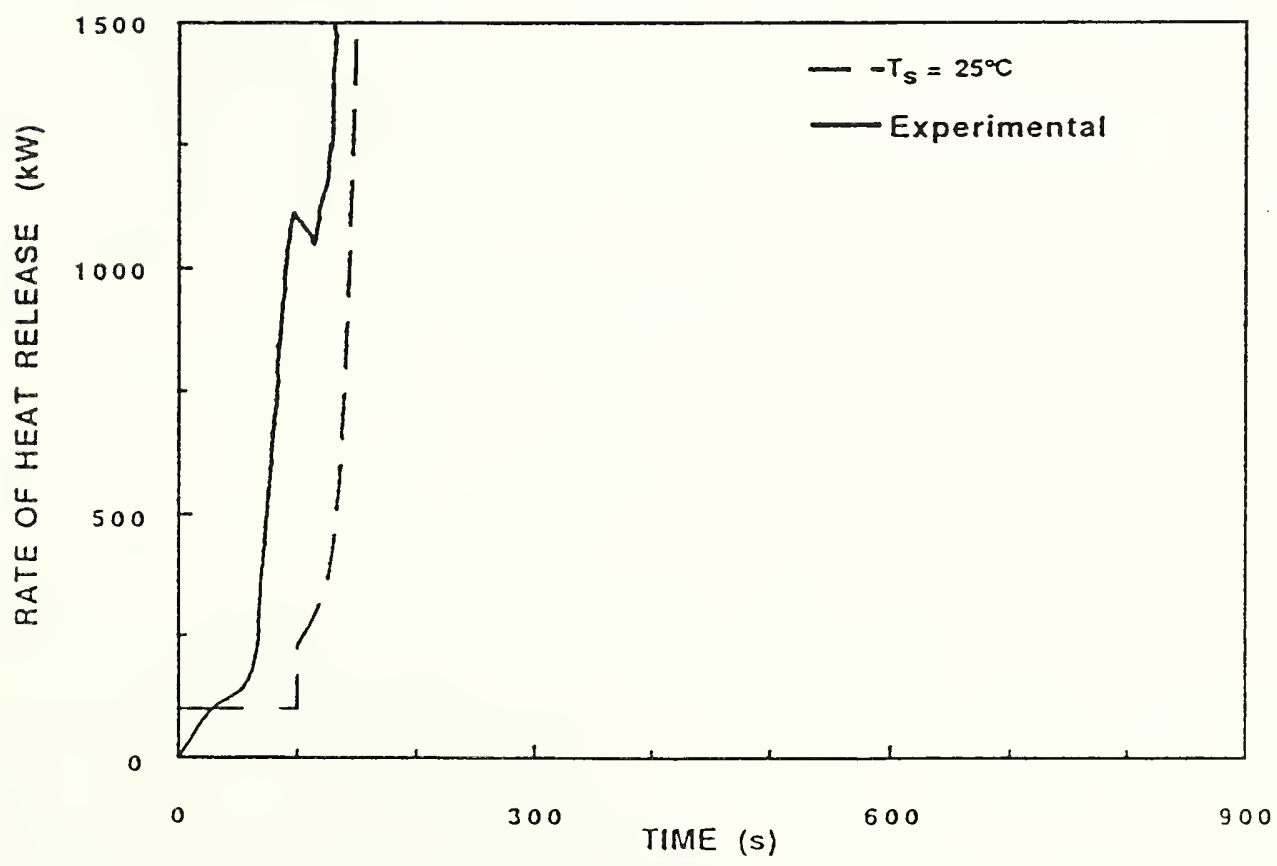

Figure A-12. Rate of heat release vs. time for expanded polystyrene lined room fire. 
Figure B-1 shows surface temperature measurements for a PMMA room wall fire performed at NIST [12]. The (x) symbols denote the locations of the $0.25 \mathrm{~mm}$ chromel-alumel thermocouples, the (o) symbols denote the locations of heat flux gages. The numbers indicate the time in seconds from the start of the test to the time when the thermocouple reads a surface temperature of $378^{\circ} \mathrm{C}$. This temperature is used as the critical surface temperature at ignition. The underlined numbers indicate the time in seconds for the heat flux gage to register a heat flux of $15 \mathrm{~kW} / \mathrm{m}^{2}$. Table $B-1$ is an estimate of pyrolysis area as a function of time for this experiment. These values are plotted in Figure 4 as the experimental values. 
Table B-1

Pyrolysis area estimated from thermocouple data

\begin{tabular}{lc}
$\begin{array}{c}\text { Time } \\
(\mathrm{s})\end{array}$ & $\begin{array}{c}\text { Pyrolysis Area } \\
\left(\mathrm{m}^{2}\right)\end{array}$ \\
\hline 245 & 0.19 \\
345 & 0.28 \\
435 & 0.40 \\
520 & 0.47 \\
580 & 0.56 \\
675 & 1.39 \\
700 & 1.95 \\
750 & 3.62 \\
800 & 4.18
\end{tabular}




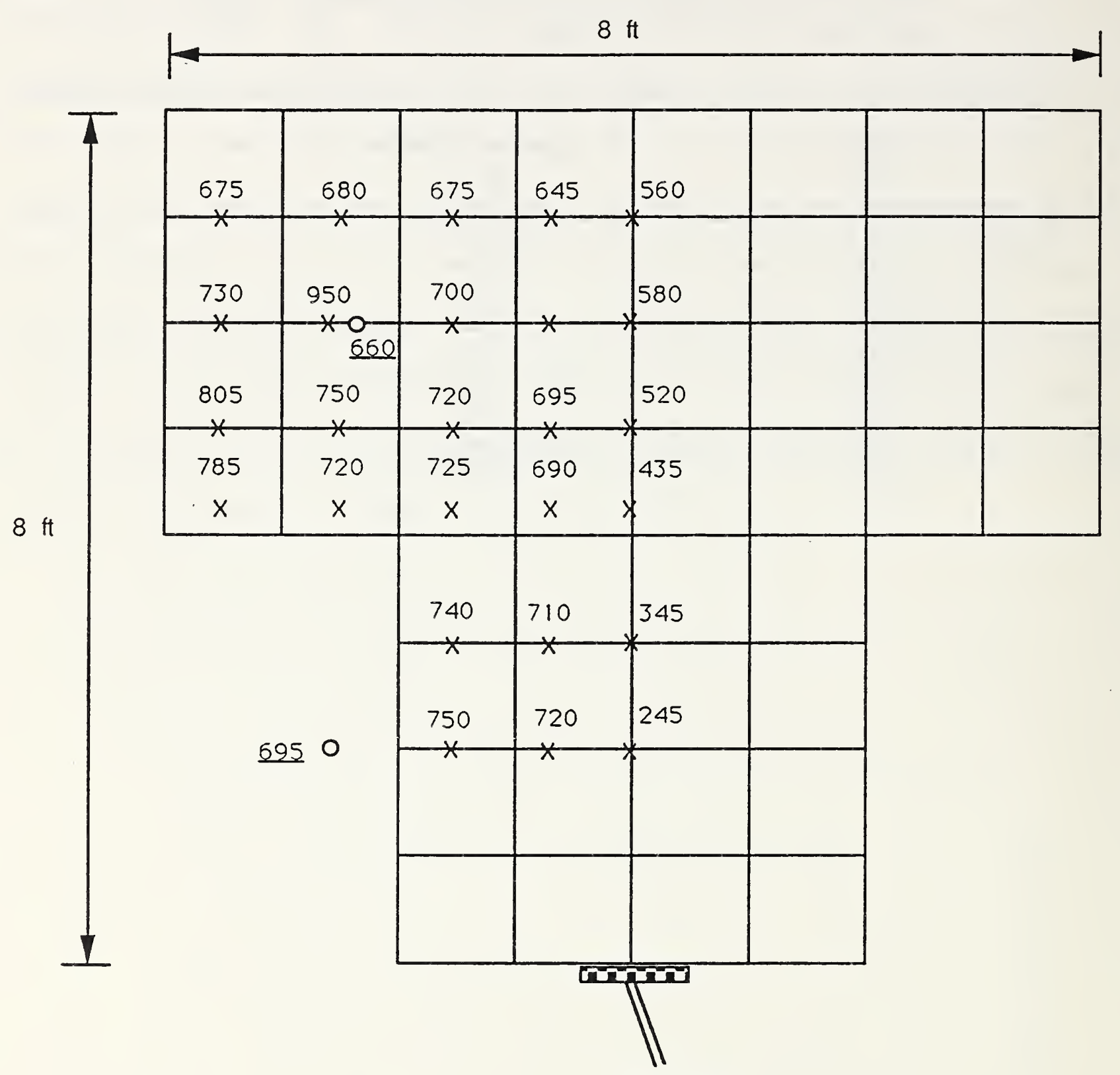

line burner

Figure B-1. Time to reach ignition temperature at various positions for flame spread on a PMMA wall section in an enclosure. 


\begin{tabular}{|c|c|c|}
\hline \multirow{3}{*}{\multicolumn{2}{|c|}{$\begin{array}{c}\text { U.S. DEPARTMENT OF COMMERCE } \\
\text { NATIONAL INSTITUTE OF STANDARDS AND TECHNOLOGY }\end{array}$}} & \multirow{2}{*}{ 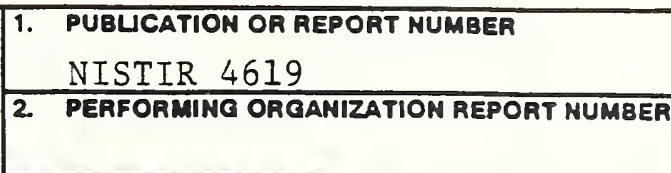 } \\
\hline & & \\
\hline & & $\begin{array}{l}\text { 3. PUBLCATION DATE } \\
\text { August } 1991\end{array}$ \\
\hline \multicolumn{3}{|c|}{$\begin{array}{l}\text { 4. TITLE AND SUBTITLE } \\
\text { A Framework for Utilizing Fire Property Tests }\end{array}$} \\
\hline \multicolumn{3}{|c|}{ Thomas G. Cleary and James G. Quintiere } \\
\hline \multirow{2}{*}{\multicolumn{2}{|c|}{$\begin{array}{l}\text { 6. PERFORMING ORGANIZATION (IF JOINT OR OTHER THAN MIST, SEE INSTRUCTIONS) } \\
\text { U.S. DEPARTMENT OF COMMERCE } \\
\text { NATIONAL INSTITUTE OF STANDARDS AND TECHNOLOQY } \\
\text { GAITHERSBURG, MD 20899 }\end{array}$}} & 7. CONTRACT/GRANT NUMBER \\
\hline & & 8. TYPE OF REPORT AND PERIOD COVERED \\
\hline \multicolumn{3}{|c|}{ 9. SPONSORING ORGANIZATION MAME AND COMPLETE ADDRESS (STREET, CITY, STATE, ZIP) } \\
\hline
\end{tabular}

10. SUPPLEMENTARY NOTES

11. ABSTRACT (A 200-WORD OR LESS FACTUAL SUMMARY OF MOST SIONIFICANT INFORMATION. IF DOCUMENT INCLUDES A SIONIFICANT BIBLOGRAPHY OR LTERATURE SURVEY, MENTION IT HERE)

A complete approximate set of equations is developed to describe fire spread and its resultant energy release over a surface. Wall, floor, and ceiling orientations are considered. The needed model data are couched in terms of available test method results, e.g., Cone Calorimeter and LIFT apparatuses. Several applications are presented to show how energy release rates can be predicted and how well they represent real data from full-scale and model room lining experiments.

12. KEY WORDS (6 TO 12 ENTRIES; ALPHABETICAL ORDER; CAPITALZE OMLY PROPER MAMES; AND SEPARATE KEY WORDS BY SEMICOLONS)

Heat release; flammability tests; fire predictions; linings; room fires

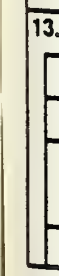

\section{AVALABIUTY}

\section{UNUMITED}

FOR OFFICIAL DISTRIBUTION. DO NOT RELEASE TO MATIONAL TECHMICAL INFORMATION SERVICE (NTIS).

ORDER FROM SUPERINTENDENT OF DOCUMENTS, U.S. COVERNMENT PRINTING OFFICE, WASHINGTON, DC 20402.

ORDER FROM NATIONAL TECHNICAL INFORMATION SERVICE (NTIS), SPRINGFIELD, VA 22161.
14. NUMBER OF PRINTEO PACES

36

15. PRICE

$\mathrm{A03}$ 



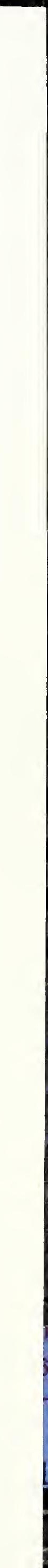


